\title{
DISCRIMINACIÓN VISUAL COMO DETERMINANTE DE ESTILO Y ASIGNACIÓN TIPOLÓGICA DE LA CERÁMICA CÓDICE DE CALAKMUL, CAMPECHE
}

\author{
SYLVIANE BOUCHER \\ Yoly Palomo \\ Centro InAH Yucatán
}

Resumen: Los aproximadamente 600 fragmentos de cerámica de estilo códice recuperados por el Proyecto Arqueológico Calakmul, corresponderían a un mínimo de 86 vasijas. La mayoría proviene de contextos asociados al palacio, Estructura XX, de la Gran Acrópolis donde, probablemente, se celebraban importantes eventos sociales y políticos entre la aristocracia maya, como se ha planteado.

Los análisis químicos de pasta de cerámica códice han dado como resultado divisiones principales dentro de ésta, aunque se ha propuesto como único foco de fabricación la región de la cuenca de El Mirador.

Los nuevos hallazgos en Calakmul nos permiten cuestionar el origen único de este estilo. Mientras que se generan datos comparativos para una caracterización de las huellas químicas de pasta, proponemos un análisis con base en modas cerámicas y en el sistema Tipo-variedad.

Palabras clave: Calakmul, cerámica, códice, modas, tipología.

ABSTRACT: This paper, primarily, addresses the approximately 600 codex style sherds recovered during the Calakmul Archaeological Project. These sherds make up a minimum of 86 vessels. The majority of these come from archaeological contexts associated with the palace structure known as Structure XX in the Great Acropolis, where important social and political events took place among maya aristocracy.

Paste chemical analysis of codex style ceramics have resulted in several divisions. Nevertheless it was proposed that they formed an homogeneous group, with one focus of production, El Mirador Basin.

New discoveries in Calakmul permit us to question the premise of a single origin for this style. While new comparative data is generated from paste characterization of chemical fingerprints, we propose an analysis based on concepts of ceramic modes and the Type-variety system.

Kerwords: Calakmul, ceramics, codex, modes, typology.

RECEPCIÓN: 31 de agosto del 2010.

ACEPTACIÓn: 2 de febrero del 2011. 



\title{
DISCRIMINACIÓN VISUAL COMO DETERMINANTE DE ESTILO Y ASIGNACIÓN TIPOLÓGICA DE LA CERÁMICA CÓDICE DE CALAKMUL, CAMPECHE
}

\author{
SYLVIANE BouChER \\ Yoly Palomo \\ Centro InAH Yucatán
}

\section{Introducción}

En el pasado el estudio de la cerámica de los antiguos mayas se restringía al análisis de los sistemas de distribución y consumo. Actualmente, las investigaciones de composición de pasta, que analizan variabilidad química, han logrado identificar sitios de producción específicos, apoyados en la comprensión de los procesos humanos que subyacen en la formación del registro arqueológico. Esto es imprescindible para formular interpretaciones significativas de los datos empíricos generados por los estudios composicionales de pasta cerámica.

Después de treinta años de investigaciones composicionales de pasta por activación neutrónica, en una interacción entre ciencia analítica, arqueología, epigrafía, antropología e historia del arte, Bishop (1992: 51) y Reents Budet et al. (s.f.: 4) reconocen que sólo en combinación con contextualizaciones arqueológicas precisas se revelan patrones significativos. De tal forma, la complejidad conceptual y metodológica de estudios composicionales en el área maya ha sido reforzada por investigaciones que reconocen las variables de los contextos natural, económico, social, ideológico e histórico.

No obstante, las evidencias epigráficas y la interpretación de datos arqueológicos fragmentarios aunados al análisis composicional de pasta, han desatado una polémica alrededor del origen del llamado "reino de Kaan" y el controversial policromo de "estilo códice", ${ }^{1}$ asociado con él. Empero, no se pone en duda que Calakmul, cuyo glifo emblema y secuencia dinástica se encuentran en esta cerámica, fue la sede de la poderosa dinastía de la Serpiente durante el Clásico Tardío (Carrasco, 2008).

La llamada "cerámica códice" ostenta un estilo narrativo exquisito, cuya espectacularidad llegó a ser reconocida, a principios de la década de los setenta,

\footnotetext{
${ }^{1}$ Coe (1973: 91) conjeturó que los pintores de la superficie curva de estas vasijas eran los mismos que los de los libros biombo mayas.
} 
por coleccionistas en los mercados internacionales de arte - aunque la carencia de contextos arqueológicos llevó a algunos mayistas a pensar que eran falsificaciones (Hansen, Bishop y Fahsen, 1991: 225)—. A finales de esa década el origen de esta cerámica todavía era desconocida.

No fue sino hasta 1979 que algunos tiestos de estilo códice se recuperaron en una cala de saqueo en el sitio de El Mirador (Forsyth, 1989: 110-114, 133, 136) y fueron analizados por activación neutrónica de elementos traza (Bishop, 1984: 104). Basándose en un perfil químico generalizado, es decir, un modelo composicional regional, Reents Budet y Bishop (1987) sugirieron como origen de la cerámica códice la región entre El Mirador y Pacaya. Establecieron dos subgrupos químicos que reflejaban recetas de pasta los cuales, al parecer, han definido la producción de cerámica de este estilo: un subgrupo mayor que representaba la de Nakbé y el otro, menor, que se relacionaba con El Mirador y sitios cercanos como Pacaya y Tintal (Reents Budet, Martin, Hansen y Bishop, 1997).

En 1987, el proyecto Regional Archaeological Investigation of North Peten, Guatemala (RAINPEG), de Richard Hansen, recuperó tiestos y una vasija semicompleta de estilo códice en trincheras de saqueo asociados a un conjunto "residencial" de Nakbé, denominado Grupo Códice (Hansen, Bishop y Fahsen, 1991: 227). Según Carrasco (2008: 9), los análisis de Reents Budet y Bishop fueron los que "incitaron" a Hansen a interpretar al Grupo Códice como la residencia y "taller" de artistas de la élite que producían alfarería de estilo códice, pues no se reportó evidencia arqueológica para sustentar este punto de vista, además de unos cientos de tiestos, la presencia negativa de una gran cantidad de calas de saqueo y un vaso fragmentado con una composición química anómala (cf. Hansen, Fahsen y Bishop, 1992: 302; López y Fahsen, 1994). Sin embargo, a partir de ese momento, se ha considerado como origen primario de la cerámica códice el sitio de Nakbé en la cuenca de El Mirador (cf. Reents Budet et al., 1998).

Hoy día, datos arqueológicos y químicos indican que otros sitios de la cuenca al oeste y noroeste de Nakbé como Zacatal, Pacaya, La Florida y Porvenir, también tuvieron talleres de esta cerámica (Reents Budet et al., s.f.: 11; Forsyth, 2002: 665). Otros sitios con cerámica códice, como Tintal y El Mirador, son preclásicos con pequeños componentes dispersos del Clásico Tardío, los cuales probablemente fueron reocupados para venerar ancestros. Además, hay otros como La Muerta, al noreste de Nakbé, donde se halla una necrópolis con artefactos exóticos asociados a la cerámica códice; y La Muralla, donde sólo se ha recuperado un tiesto de dicha cerámica (Reents Budet et al., s.f.: 12-16).

Otros sitios fuera de la cuenca de El Mirador donde se ha reportado cerámica códice son el Zotz y Uaxactún (Reents Budet et al., s.f.: 25). Recientemente, se han reportado algunos fragmentos en Uxul y El Perú (Grube y Paap, 2008) (ver mapa, figura 1).

El Proyecto Arqueológico Calakmul, dirigido por Ramón Carrasco, recuperó 766 tiestos, cuatro vasijas semicompletas y una completa, sin considerar los encontrados por el proyecto de William Folan. Esto ha llevado a cuestionar la 


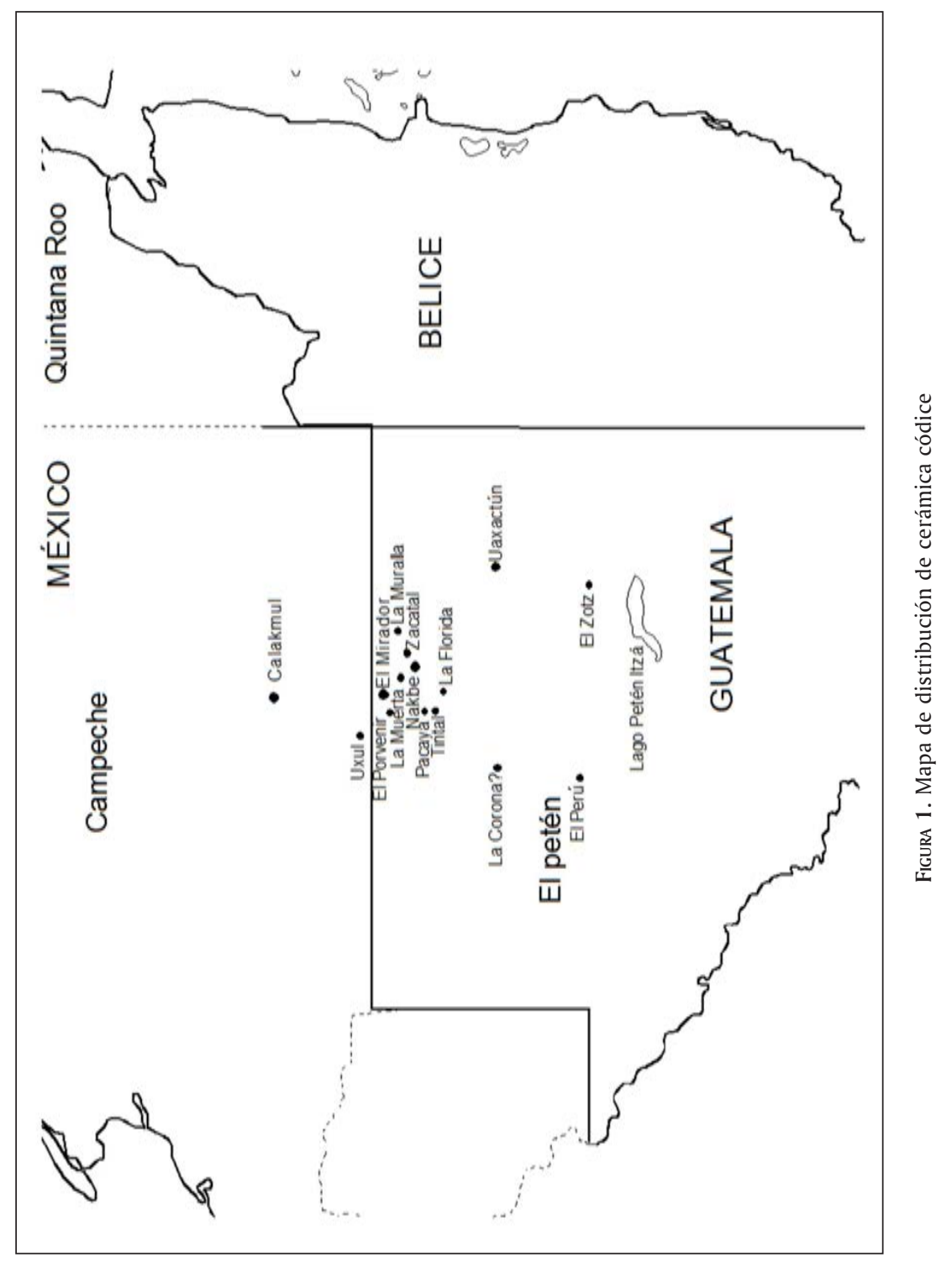


ubicación exclusiva del origen de este estilo en sitios de la cuenca de El Mirador (García y Carrasco, 2006: 126; Delvendahl, 2003, 2005: 463, 2008: 34; Carrasco, 2008), ya que en la arqueología se ha aceptado como premisa el uso juicioso del criterio de relativa abundancia de un producto para sugerir la fuente probable de origen (Bishop, 1992: 15).

Por otro lado, ya que el problema de origen radica en la asignación a priori de la huella química de los fragmentos recuperados en Nakbé, como si representaran únicamente vasijas del "auténtico" estilo códice, y puesto que el perfil químico de los de Calakmul son sólo "copias" (cf. Reents Budet y Bishop, en Carrasco et al., 1998: 165), queremos reevaluar los aciertos y limitaciones de los análisis composicionales enfocados en la tradición policroma. También deseamos someter a revisión el recuento cronológico realizado por dichos estudios de la cerámica códice recuperada en sitios de la cuenca de El Mirador y Calakmul, así como sus implicaciones. Asimismo, expondremos nuestra metodología de trabajo en el marco del sistema tipo-variedad; también presentaremos un análisis empírico, plasmado en un cuadro, donde se contrastan atributos de vasijas de cerámica códice sin y con origen de fabricación (recuperadas en Calakmul). ${ }^{2}$

\section{Análisis tipo-variedad}

El método tradicional para analizar cerámica maya, incluyendo la policroma, de interés aquí, es el sistema tipo-variedad. Fue diseñado para ser flexible y permitir el análisis y la descripción en distintos niveles: un grado detallado enfocado en la variedad y otro más general orientado en el tipo, entre otros de mayor abstracción. Y aunque ha habido muchas quejas sobre él, pocos ceramistas lo evaden. Complementar el sistema tipo-variedad con aspectos estilísticos de historia del arte y análisis composicional de pasta, como lo han hecho Reents Budet y Bishop, ha demostrado ser útil para acercarnos a la dimensión sociohistórica que Smith y Gifford (Smith et al., 1960; Smith y Gifford, 1966) previeron como objetivo final de este método analítico (Reents Budet y Bishop, 2003: 93).

El sistema tipo-variedad ha sido útil para recuperar información cronológica y espacial. Sin embargo, ha mostrado menos éxito para revelar la dinámica de la interacción sociopolítica, codificada en los tiestos y/o vasijas. Especialmente difícil resulta descubrir las dimensiones a nivel de sitio específico y personas, que son las que revelan rasgos sociohistóricos (Reents Budet y Bishop, 2003: 94). Gifford (1976: 33) había insistido en que el ceramista debe conceptualizar y asignar nomenclatura tipológica como si estuviera clasificando vasijas enteras. No obstante, en el trabajo arqueológico la ubicua clasificación de fragmentos,

\footnotetext{
${ }^{2}$ Cabe mencionar que tuvimos acceso a manuscritos todavía inéditos, amablemente proporcionados por Reents Budet, Martin, Hansen y Bishop (s.f.), así como por Bishop et al. (s.f.), respectivamente.
} 
así como el hecho de no tener acceso a suficientes vasijas enteras o de no hacer referencia a las saqueadas, ha impedido la identificación de atributos estilísticos de producción de cerámica pintada en el tiempo y espacio, a excepción de algunos reconocidos ejemplos ( $c f$. Reents Budet et al., 1994). Esto evidencia el fracaso del sistema que debería permitir integrar los datos del análisis descriptivo a los más complejos niveles de abstracción, donde se pueden inferir unidades socioculturales de la cerámica (Reents Budet y Bishop, 2003: 95-96).

Ball (1993: 258-269) también ha reconocido que todavía no hemos apreciado el potencial de las cerámicas clásicas mayas para revelar datos específicos sobre su uso, los sistemas cerámicos de producción, el consumo y la economía y la política del Clásico. Por ello sugiere añadir al tradicional sistema clasificatorio otro nivel de análisis enfocado en la cerámica pintada, que denomina "subcomplejos de escuela-palacio" y "tradiciones artesanales de comunidades rurales", y que correspondería a la vinculación de grupos policromos específicos con sitios individuales. Por lo tanto, recomienda una mayor diferenciación entre vasijas pintadas producidas y circuladas localmente respecto a sus contrapartes más exóticas (Reents Budet y Bishop, 2003: 97).

Dentro del sistema tipo-variedad se distinguen vasijas y tiestos de un sitio respecto a los de otro, designando con un nombre de variedad diferente los ejemplos que se presumen locales. ${ }^{3}$ Gifford (1976: 32) había sugerido que la categoría de variedad se correlacionaba con el estilo de un individuo (artesano o artista), el tipo con el estilo de un pequeño grupo (taller especializado) y el grupo cerámico con las actividades cerámicas comunes de una comarca.

De acuerdo con el sistema tipo-variedad, la cerámica de estilo códice se clasificaría dentro del grupo Zacatal o Palmar, dependiendo del color de su engobe base (Ball en Reents Budet et al., 1994: 362-365; Forsyth, 1989: 112, 133; 1993: 50); por ello tradicionalmente se ubicó en el periodo cerámico Tepeu 2 (672-830 d.C.; Smith y Gifford, 1966: 164, 172). No obstante, Reents Budet, Martin, Hansen y Bishop (1998: 8-9), con base en las fechas de Cuenta Larga y Corta de las vasijas, determinaron que la producción de este estilo se restringía a la primera mitad de Tepeu 2, del Katun 9. 12. 0. 0. 0. al 9. 15. 0. 0. 0, o sea, 672-731 d.C.

Por su parte, Forsyth $(1989 ; 1993)$ ha planteado recientemente $(2002: 673)$ que la cerámica de la distintiva tradición pictórica negra y roja sobre engobe crema de fina línea modulada, conocida como estilo códice, anteriormente subsumida en el tipo Zacatal ${ }^{4}$ Crema Policromo (Hansen, Bishop y Fahsen, 1991: 225; López y Fahsen, 1994: 69; Ball en Reents Budet et al., 1994: 316, 324-326,

\footnotetext{
${ }^{3}$ También se usa el muy trillado y ambiguo "Variedad No Especificada" cuando no se tiene posibilidades de comparación, y la designación "Demasiado Excepcional o Poco Común para Caracterización Tipológica” (cf. Ball en Reents Budet et al., 1994: 364-365); o, peor aún, se emplean asignaciones tipológicas forzadas que resultan equívocas (Véase Taschek y Ball 1992: 496).

${ }^{4}$ Forsyth (1993: 34) cambió el nombre original Zacatel, asignado por Smith y Gifford (1966), para escribirlo correctamente.
} 
328, 364; Boucher y Palomo, 2000: 52), no coincide tipológicamente con esta categoría, sino que constituye "un tipo distinto, con muchas variedades, que se diferencía de Zacatal Crema Policromo en más términos que los estilísticos" (Forsyth, 2002: 673). El investigador argumenta que por su estética y su temática es suficientemente distinta de la cerámica Zacatal Crema Policromo y amerita una nueva designación tipológica, con lo cual concordamos plenamente. ${ }^{5}$

\section{Análisis composicional de pasta}

El corpus de vasijas pintadas del Clásico Tardío es grande e incluye distintos estilos de pintura. Sin embargo, investigaciones estilísticas de vasijas a menudo sin contexto arqueológico, y químicas enfocadas en la composición de la pasta, han logrado aislar grupos menores que sugieren la ubicación de "talleres" donde fueron creados los distintos grupos y/o estilos de pintura (Reents Budet y Bishop, 2003: 98).

En la publicación paradigmática Maya Scribe and His World, de Coe (1973), se sugiere que las vasijas pintadas se crearon para acompañar a la élite en sus tumbas y que sus escenas se relacionaban con el inframundo como había sido descrito en el Popol Vuh, libro maya quiché del siglo xvi. Siguiendo esta teoría, en 1981 Robicsek y Hales publicaron un corpus fotográfico de 308 vasijas del denominado estilo códice. Utilizando criterios estilísticos, atribuyeron algunas vasijas a pintores individuales y otras a cuatro áreas dispersas de producción (Robicsek y Hales, 1981: xxi, 235-237; Bishop, 1992: 42). Bishop evaluó mediante activación neutrónica 59 de estas piezas y concluyó que los datos eran consistentes con una fuente generalizada de producción; empero, aconsejó muestrear más ejemplos para poder tomar en cuenta covariaciones (Robicsek y Hales, 1981: 239-240).

Años más tarde, Reents Budet y Bishop implementaron el Maya Polychrome Ceramics Project, del Smithsonian Center for Materials Research and Education, para registrar variación composicional de pasta a través el área maya, proporcionando datos sobre producción de cerámica policroma por medio de patrones de consumo de la élite. La posibilidad de evaluar la coherencia composicional o su ausencia entre miembros de grupos definidos estilísticamente, implicaba la existencia de "talleres" y potencialmente de estilos individuales de pintura (Bishop, 1992: 38).

Para 1992, Bishop (39) había procesado 12000 muestras que incluían 1600 vasijas completas. Aunque la base de datos era grande, el muestreo, desafortunadamente, había sido fortuito y variable. Para 1994, Reents Budet, Bishop y Fahsen (1994: 52) reportaban 8000 tiestos y 1700 vasijas completas de cerámica policroma muestreadas. Mientras que en el año 2000 se contaba con un banco

\footnotetext{
${ }^{5}$ Aunque recientemente Ball sugirió una nueva categoría designada como "Grupo Cerámico Zacatal: fondo crema estilo códice" (Ball en Reents Budet et al., s.f.: 47), no toma en cuenta los colores más comunes de cerámica códice y, por lo tanto, no es funcional.
} 
de datos basado en 14000 muestras (Reents Budet et al., s.f.: 22), sin especificar el porcentaje que correspondía a cerámica de estilo códice.

En su nivel más básico, los análisis químicos de pasta proporcionan datos cuantitativos de sus elementos constitutivos. Dichos datos no nos dicen dónde una muestra cerámica fue fabricada o cuáles fueron sus movimientos después de ser elaborada o aún el sentido que reviste la similitud composicional que pueda tener con otra. Por lo tanto, los investigadores pocas veces pueden discernir sin ambigüedad un patrón que representaría una interpretación arqueológica directa (Bishop, 2003: 89).

La habilidad para hacer inferencias sobre el comportamiento del pasado depende de nuestro entendimiento de la relación entre la manifestación física de los artefactos y los aspectos intangibles de la cultura y sociedad. De acuerdo con Reents Budet y Bishop (2003: 99), una variabilidad estilística dentro de un grupo implicaría que las vasijas son productos de distintos talleres y artesanos que tuvieron diferentes grados de interacción en su producción y en sus relaciones sociopolíticas durante el Clásico Tardío. Y si los perfiles químicos de las vasijas del mismo grupo son diferentes es porque representan distintas fuentes de barro, así como diversas cantidades y variedades de desgrasantes y/o sus mezclas (Hansen, Fahsen y Bishop, 1992: 300-301). En general, los resultados químicos deberían apoyar la hipótesis de la historia del arte: que las vasijas son productos de distintos artistas y talleres en un área relativamente grande, caracterizada por recetas idiosincrásicas de pasta y/o diferencias tecnológicas.

Dentro de estas limitaciones, de acuerdo con Reents Budet, Martin, Hansen y Bishop (s.f.: 23), las Tierras Bajas Mayas se caracterizan por sus depósitos variables de arcillas y cada sitio arqueológico está rodeado por fuentes de aquellas cuya composición química es distinguible. Con base en la caracterización composicional de grupos se ha podido diferenciar la cerámica producida en sitios separados por solamente unos kilómetros (Bishop, 1992: 39). Por ejemplo, hay notable diferencia en la pasta obtenida de los tiestos de estilo códice de El Mirador y los de Nakbé separados por un gran bajo de $14 \mathrm{~km}$ (Hansen, Fahsen y Bishop, 1992: 300).

Es probable que muchos de los factores mencionados previamente incidían en la diversidad química de los subconjuntos de cerámica códice, lo que a su vez implicaría una producción en diversos centros. Además de distinguir entre distintos lugares de fabricación de la cuenca del Mirador, hoy se indagan las relaciones interregionales.

En contraposición, vasijas hechas por un mismo artesano o taller tendrían que traslaparse en el mismo espacio "euclidiano" siempre y cuando estuvieran fabricadas con los mismos materiales y preparadas con la misma receta. Cuando los subgrupos presentan pequeñas distancias euclidianas ${ }^{6}$ denotan una alta similitud y se consideran como "grupo de referencia" (Reents Budet y Bishop, 2003: 101).

\footnotetext{
${ }^{6}$ Las distancias euclidianas se calculan a partir de concentraciones de elementos traza, transformadas logarítmicamente.
} 
Reents Budet y Bishop (2003: 99) reconocen que cuando muestras cerámicas de un sitio han sido tomadas a través de varios años, como en el caso de Calakmul, las más recientes requieren una reevaluación de los patrones observados anteriormente. Por ello el conjunto de datos puede evolucionar debido a la inclusión de subgrupos; es decir, en la medida en que aquél se incrementa y se afina, las tendencias estadísticas se vuelven más representativas. ${ }^{7}$

\section{Breve historia de la determinación composicional de cerámica códice}

En 1984 la matriz de datos de El Mirador comprendía cerámica con desgrasante de carbonatos así como ceniza volcánica. Había ejemplares en la muestra del tipo Zacatal Crema Policromo, que incluían cerámica pintada estilo códice (Bishop, 1984: 105), aunque se asemejaba a la cerámica local, parecía ser un poco divergente. Bishop (1984: 105, fig. 52) admitió que en esta etapa del análisis lo plasmado en la gráfica era una arcilla regional en vez de una caracterización composicional de sitio.

Estos dos grupos, el Zacatal que incluye la cerámica de estilo códice y el grupo de referencia que representa a la cerámica local, mostraban un alto grado de correlación. Por ello Bishop concluyó que el primero parece haber sido producido y "ampliamente intercambiado" en la subregión norte del Petén (1984: 105, núm. 6 y 1; 110-111).

Hoy en día han sido analizadas aproximadamente 700 muestras de los sitios de la cuenca de El Mirador; pero Bishop, Blackman, Hansen, Reents Budet y Sears (s.f.: 2) admiten que fueron coyunturales. ${ }^{8}$ Aunque en ellas las variaciones químicas de la cerámica códice fueron significativas, no sabemos el porcentaje correspondiente a este estilo dentro de las mencionadas muestras. Este hecho confirmaba, para Bishop, la existencia de múltiples talleres y fuentes de arcilla en un área relativamente pequeña (Pallan y Velásquez, 2005: 533). No obstante, Reents Budet, Martin, Hansen y Bishop (s.f.: 23) ahora precisan en una especie de silogismo que por ser producida en un tiempo relativamente corto (durante no más de dos generaciones) la variabilidad química probablemente no se debió a cambios en la procuración de materias primas o recetas de pastas, sino más bien a su producción, en distintos talleres ubicados en diversos sitios dentro de la cuenca de El Mirador.

En 1987 los resultados del análisis de 120 vasijas códice llevaron a Reents Budet y Bishop (1987: 775) a concluir que este estilo provenía de una región al

\footnotetext{
${ }^{7}$ Es importante tomar en consideración que Reents Budet y Bishop (2003: 100) han admitido que 179 vasijas, de las cuales 59 no tienen procedencia, posiblemente representan una muestra "inadecuada".

${ }^{8}$ En el año 2000 Reents Budet et al. (s.f.: 24) admitieron que todavía faltaban muestras para caracterizar la producción de sitios específicos dentro de la cuenca como El Mirador, Pacaya y Tintal.
} 
norte noroeste de Uaxactún y sur de El Mirador. El apoyo para esta conclusión se obtuvo a partir de las excavaciones de Hansen en Nakbé, donde se recuperó cerámica códice en contexto arqueológico (Hansen, Bishop y Fahsen, 1991).

Entre la cerámica recuperada por Hansen había un vaso, semicompleto, con escenas de escribas (Hansen, Bishop y Fahsen, 1991: 230, fig. 5-6; Forsyth, 1993: 51, fig. 18), casi idéntica a otras previamente ilustradas por Robicsek y Hales (1981, vasijas núms. 62 y 63). Dado que las escenas eran muy similares, se podía pensar que fueron pintadas por unos cuantos artistas; además, si las vasijas fueron producidas con los mismos materiales, entonces se podía plantear la posible existencia de un "taller" especializado en esta variante (Bishop, 1992: 43).

En 1991 se llevó a cabo un análisis "factorial” de las concentraciones químicas de 154 muestras de estilo códice, incluyendo 10 con escenas de escribanos así como la procedente de Nakbé, tiestos de El Mirador y Pacaya y una muestra de barro del primer sitio (Hansen, Bishop y Fahsen, 1991: 234, 238; Hansen, Fahsen y Bishop, 1992: 301). Curiosamente, el vaso difería composicionalmente de toda la cerámica códice previamente analizada (Hansen, Bishop y Fahsen, 1991: 239; Bishop, 1992: 41; Hansen, Fahsen y Bishop, 1992: 302; Bishop, comunicación personal, 2009). Al final, las vasijas con el tema de escribanos mostraron poca similitud composicional entre sí, reduciendo la posibilidad de un solo taller fabricante (Bishop, 1992: 41). La distribución de esas muestras hizo suponer como focos de producción, además de a Nakbé y a El Mirador, a Pacaya (véase Hansen, Fahsen y Bishop, 1992: 301-302, fig. 3). Cabe resaltar que las vasijas códice sin procedencia arqueológica se agruparon con las de El Mirador.

Es interesante notar que, dada la composición tan poco usual de aquel vaso, podría estar fabricado con materia prima de áreas a considerable distancia de Nakbé o con material cuya composición química estuviera fuera de los límites de la sensibilidad del análisis. O quizás representaba un ejemplo excepcional asociado a un artista en particular o quizá fuese importado de un sitio todavía no estudiado (Hansen, Fahsen y Bishop, 1992: 302). Lo que en ese momento era precisamente el caso de Calakmul.

Para 1992 la conclusión sobre la variación existente era que había múltiples fuentes de arcilla en el norte del Petén explotadas para fabricar cerámica códice, y que la composición química de las muestras de Nakbé era distinta a las provenientes de sitios cercanos. Por ende, la producción de este estilo no sería obra de un solo taller sino el resultado de varios talleres especializados en una multiplicidad de lugares (Hansen, Bishop y Fahsen, 1991: 241; Hansen, Fahsen y Bishop, 1992: 302).

La cerámica policroma de Nakbé presenta una matriz con $35 \%$ de carbonatos de calcio, en tanto la de Calakmul muestra concentraciones de calcio de entre $15 \%$ y $38 \%$. Bishop et al. (s.f.: 11) admiten que la cerámica de El Mirador es más similar a la de Calakmul que a la de Nakbé. Como las concentraciones de calcio de Calakmul y Nakbé se pueden traslapar, la concentración de cromo está considerada un contraste, aunque no absoluto, que puede verse en la gráfica (Bishop et al., s.f.: fig. 8), donde la cerámica de Calakmul está a la derecha de la línea 
por presentar más altas concentraciones de cromo. ${ }^{9}$ También se puede ver que la cerámica códice se concentra mayormente con la de la cuenca de El Mirador a la izquierda.

Cuando los datos de las 169 muestras de vasijas códice, sin procedencia arqueológica, se incluyen en la gráfica (Bishop et al., s.f.: fig. 9), diversos pequeños grupos se aglutinan del lado izquierdo debido a las concentraciones más altas de calcio de Nakbé. Es de notar que únicamente dos vasijas sin procedencia muestran una similitud composicional con las de Calakmul, reforzando las interpretaciones iniciales de Reents Budet y Bishop (1987) y Hansen, Bishop y Fahsen (1991: 241) que adjudicaron el origen de fabricación de la mayoría de cerámica códice a la cuenca de El Mirador, con base en muestras más reducidas.

Bishop et al. (s.f.: 13) concluyen enfatizando el fuerte consumo local de cerámica códice en la cuenca. En cambio, ahora planteamos también evidencia de contactos con regiones como la de Calakmul (aproximadamente $38 \mathrm{~km}$ al norte de El Mirador) y la posibilidad de que este último sitio haya sido productor de este estilo o una variante de él.

Como habíamos mencionado previamente, más del $80 \%$ de las muestras de cerámica códice forma dos subgrupos que básicamente reflejan dos recetas de pasta que definen la producción de esta tradición: el más grande representa la producción de Nakbé e incluye cientos de tiestos (tanto del estilo códice como de otros tipos), tres tiestos de El Mirador, dos de Pacaya así como algunas vasijas sin contexto arqueológico (Reents Budet, Martin et al., s.f.: 23-24). El grupo más pequeño incluye básicamente tiestos de los dos últimos sitios así como de Tintal, más algunos de Nakbé y también la mayoría de las vasijas sin contexto arqueológico. No es sorprendente que Nakbé haya exportado sus vasijas hacia El Mirador y sus sitios cercanos, y viceversa. Pero lo que sí llama la atención es la ausencia de cerámica códice fabricada en Calakmul y exportada hacia estos sitios; esto representa un patrón excepcional de aparente distribución unidireccional (Reents Budet, Martin et al., s.f.: 29), pues no tenemos la procedencia de las dos vasijas de estilo códice con perfil químico de Calakmul.

Hasta ahora, en Calakmul, Reents Budet y Bishop han muestreado 871 tiestos y/o vasijas de cerámica cotidiana, de servicio así como policroma para los proyectos de los arqueólogos Carrasco y Folan. Dentro de la última categoría se muestrearon 57 de estilo códice, lo cual representaría el $6.5 \%$ del total (aunque sólo se tienen los resultados de un $4.4 \%$ ). Es decir, todavía carecemos de los resultados del $2.1 \%$ de lo muestreado.

Anteriormente, Reents Budet, Martin et al. (s.f.: 26) habían analizado 17 fragmentos (MSK 031, MSK 036, MSK 548-MSK 559) y/o vasijas de "estilo códice" y otras estilísticamente parecidas cuya procedencia arqueológica era Calakmul.

\footnotetext{
${ }^{9}$ De acuerdo con Bishop et al. (s.f.: 11), esta gráfica incluye 22 de 26 muestras de cerámica códice de Calakmul que suponemos incluyen también cerámica del proyecto del doctor Folan.
} 
Estas piezas incluyeron tres vasos completos: dos de la estructura II $\mathrm{H}$ tumba 1 (MSK 147) y tumba 2 (MSK 155) del proyecto del doctor Folan (Folan y Morales, 1996: 18-21) y un vaso de silueta compuesta (MSK 855) del proyecto de Ramón Carrasco, recuperado de la tumba 4, en la sub II B (Boucher y Palomo, 2000: 52, 63, fig. 3). De acuerdo con información todavía no publicada, el perfil químico de la mayoría de las vasijas y fragmentos de estilo códice, excavados en Calakmul, corresponde a la producción cerámica de Nakbé (véase Reents Budet, Martin et al., s.f.: figs. 12 y 13), con la excepción de MSK 155 y MSK 855.

Las vasijas MSK 155 y MSK 855 son especialmente relevantes en la discusión de la producción y distribución de cerámica códice. La primera, el vaso con el 13 Ahau, fue considerado como códice por Folan y Morales (1996: 19) aunque su engobe de fondo es un anaranjado claro con base en gruesas pinceladas que también forman el diseño en negro, anomalías del estilo códice de fina línea sobre un engobe más claro. Por ello no consideramos este vaso como de estilo códice y no es sorprendente que su perfil químico corresponda a la producción cerámica de Calakmul. En cuanto al vaso de silueta compuesta, con paredes con depresiones en los lados opuestos al diseño (MSK 855), cuando fue descubierto nos parecía divergente por su engobe amarillo y sutil forma. Vamos a ver ahora que estos rasgos aparecen en los fragmentos muestreados con el mismo origen de fabricación que el grupo de control o que ya han sido registrados en la cuenca de El Mirador.

No obstante, Reents Budet y Bishop (en Carrasco et al., 1998: 165), Reents Budet, Martin et al. (s.f.: 27) han resaltado estos vasos, entre otros sin procedencia arqueológica, como típicos de copias locales o imitaciones del "clásico" estilo códice de la cuenca del Mirador (como MSK 855) (ver figura 5a). Excepto por el nombre en la Secuencia Primaria Estándar, el vaso de silueta compuesta parecía representativo del estilo y su perfil químico mostraba similitudes con las otras vasijas de fabricación local del ajuar de la tumba 4 de la estructura II (Reents Budet y Bishop en Carrasco et al., 1998: 165; Boucher y Palomo, 2000: 52). Reents Budet y otros sugirieron que los artistas de Calakmul ocasionalmente creaban imitaciones del "clásico" estilo códice de la cuenca, aunque con rasgos distintivos (Reents Budet y Bishop en Carrasco et al., 1998: 165; Reents Budet, Martin et al., s.f.: 27), utilizando más bien evidencia negativa para definir la producción local de cerámica códice en Calakmul.

En trabajos anteriores (Boucher, 1997: 3; Carrasco, Boucher y Álvarez, 2005: 11; Boucher y Palomo, 2000: 52) habíamos comparado este distintivo vaso con otro vaso y cajete, de estilo códice sin procedencia, y similar en color de fondo, tema, programa iconográfico y aún en la manera de aplicar la pintura ( $c f$. Robicsek y Hales, 1981: 184, vasija 170; Carlson, 1988: 287, fig. 9, 11; Reents Budet y Bishop en Carrasco et al., 1998: 166, fig. 8). Por fortuna, estas dos últimas habían sido muestreadas por Reents Budet y Bishop, quienes han hecho hincapié en su similitud química; ambos plantearon que probablemente fueron producidas como un juego, en las cercanías de Calakmul, por un solo artista posiblemente 
en contacto con el pintor del vaso de la tumba 4. Este conjunto representaría otro ejemplo de "supuestas" copias locales por parte de artistas afiliados a Calakmul.

En resumen, de acuerdo con la interpretación de los datos, la producción cerámica de Calakmul es químicamente distinguible de la de Nakbé y de todos los otros sitios de la cuenca de El Mirador. La cerámica policroma del Clásico Tardío, producida en Calakmul, se basa principalmente en una tradición de carbonatos de calcio distinta de las cerámicas con ceniza volcánica características de la cuenca del Mirador (Domínguez, 1994: 122-181; Domínguez et al., 1998: 363; Boucher y Dzul, 2006: 598). Sin embargo, Domínguez et al. (1998: 364) reportan un incremento del uso de ceniza volcánica como desgrasante en la cerámica del Clásico Tardío en Calakmul y el uso simultáneo de los dos. Por otro lado, las vasijas con desgrasante de ceniza volcánica en la cuenca del Mirador muestran perfiles de "tierras raras" significativamente más altos que los de Calakmul (Reents Budet, Martin et al., s.f.: 28).

Aunque Calakmul consumió cerámica producida en la cuenca, las muestras de sitios de esa región no presentan perfiles químicos similares a los de dicha ciudad. Aparentemente debía haber un mecanismo de intercambio que traía vasijas producidas en la cuenca a Calakmul. Pero no parece haber evidencia de reciprocidad (Reents Budet, Martin et al., s.f.: 28). Lo cual refleja un extraño patrón de producción y consumo. Además de este patrón de distribución unidireccional, datos estilísticos, químicos así como textos jeroglíicos indican fuertes relaciones entre la Cuenca y Calakmul durante el Clásico. Por lo tanto, la cerámica códice ha emergido como un indicador de conexiones ideológicas y políticas significativas capaz de informar sobre la manera en que la élite gobernante maya establecía y mantenía lazos de poder (Reents Budet, Martin et al., s.f.: 29).

\section{Metodología}

El alto porcentaje de cerámica códice recuperado por parte del Proyecto Arqueológico Calakmul hace necesario su estudio; incluye vasijas completas de tumbas, tiestos procedentes de liberación y de rellenos arquitectónicos así como de las estructuras II A, B; IV A, B, C; XV; de los conjuntos residenciales de Utsiaal Caan y Chan Chi'ich, la Plaza L y la Estructura XX del Grupo Gran Acrópolis. El contexto que mayor cantidad de fragmentos aportó, hasta el momento, fue la Estructura XX considerada como edificio de acceso al conjunto palaciego más grande de Calakmul, el llamado Grupo Gran Acrópolis (Delvendahl, 2005: 450-456; 2008: 120-128), donde se han contabilizado 704 tiestos que representan $91.90 \%$ del total de 766 de la cerámica códice recuperada por el proyecto.

Después de sucesivos intentos de agrupar los fragmentos de cerámica códice, se decidió que, de acuerdo con el sistema tipo-variedad, los tiestos, unidos o no, serían considerados como vasijas completas. Con base en lo anterior, se ela- 
boraron fichas para cada una de las piezas resultantes, con lo cual se conformó un catálogo de al menos 86 ejemplos. ${ }^{10}$ Es de notar que aún falta por integrar una categoría residual que seguramente cambiará nuestro universo de estudio, incrementándolo o disminuyéndolo.

La cédula redactada por vasija, elaborada sin predisposición hacia las muestras con origen de fabricación, detalla el o los contextos en los cuales los fragmentos fueron recuperados y contiene su asignación tipológica, sus características formales, la descripción de la decoración con lecturas de Munsell, el dibujo con perfil y un desplegado fotográfico así como un apartado de observaciones en el cual se hacen comentarios sobre la decoración, la determinación del tema plasmado, las referencias cruzadas y si la pieza fue muestreada o no, entre otros detalles. Por último, se menciona el estado de la misma y cuantos fragmentos la conforman; aquí se consideran los tiestos pegados como uno solo.

Sin embargo, sólo presentaremos el análisis de las primeras 55 vasijas pues el de las restantes están todavía en proceso. A partir de la realización del catálogo por vasija se elaboró un cuadro basado en 42 atributos donde se contrastan las características formales de igual número de piezas, sin origen de fabricación, algunas muestreadas sin resultados (en gris), contra 13 muestreadas (en 1997) con resultados (en negro) (Fase I) (ver cuadro comparativo). Cabe mencionar que entre estas últimas se tomaron en consideración, también, las vasijas núms. 77, 78 y 79 ya que forman parte de lo que consideramos nuestro "grupo de control", pues tienen resultados de origen ( $c f$. Reents Budet y Bishop en Carrasco et al., 1998: 164).

Cabe aclarar que, aparte de 3 muestras, de 1997 (Fase I) sin resultados, en 2001 (Fase II) y 2009 (Fase III), los doctores Reents Budet y Bishop realizaron 35 nuevas muestras de cerámica códice, aunque todavía no han proporcionado al proyecto los resultados.

\section{Discriminación visual de la cerámica Códice}

La mayoría de las vasijas del denominado estilo códice, muestra a menudo escenas e iconografía complejas. Limitadas por bandas glíficas y/o de cielo, las escenas pueden ser mitológicas o históricas. También existe una variante, que se conoce como "vasos dinásticos", con largas listas genealógicas (véase vasija núm. 84 en Boucher y Palomo, s.f.). Las escenas y textos jeroglíficos son trazados con una línea monocroma negra (5YR 2.5/1, 5Y 2.5/2, 7.5YR 2.5/1, 10YR 2/1), de distinto grosor e intensidad, capaz de variar a diversos tonos del color café (7.5YR 5/4, 4/4, $3 / 2$ ), rojizo oscuro (5YR 3/2) y diversas tonalidades del color gris (7.5YR 4/1, 7.5R 3/1, 10YR 3/1), trazo ejecutado con destreza, firmeza y claridad (cf. vasija núm. 0 en figura 3a).

\footnotetext{
${ }^{10}$ Cabe hacer notar que se asignaron los números de vasija, desde la primera revisión, cotejada con una fotografía; por ello, cualquier reubicación de los fragmentos quedó registrada de acuerdo con aquellos.
} 


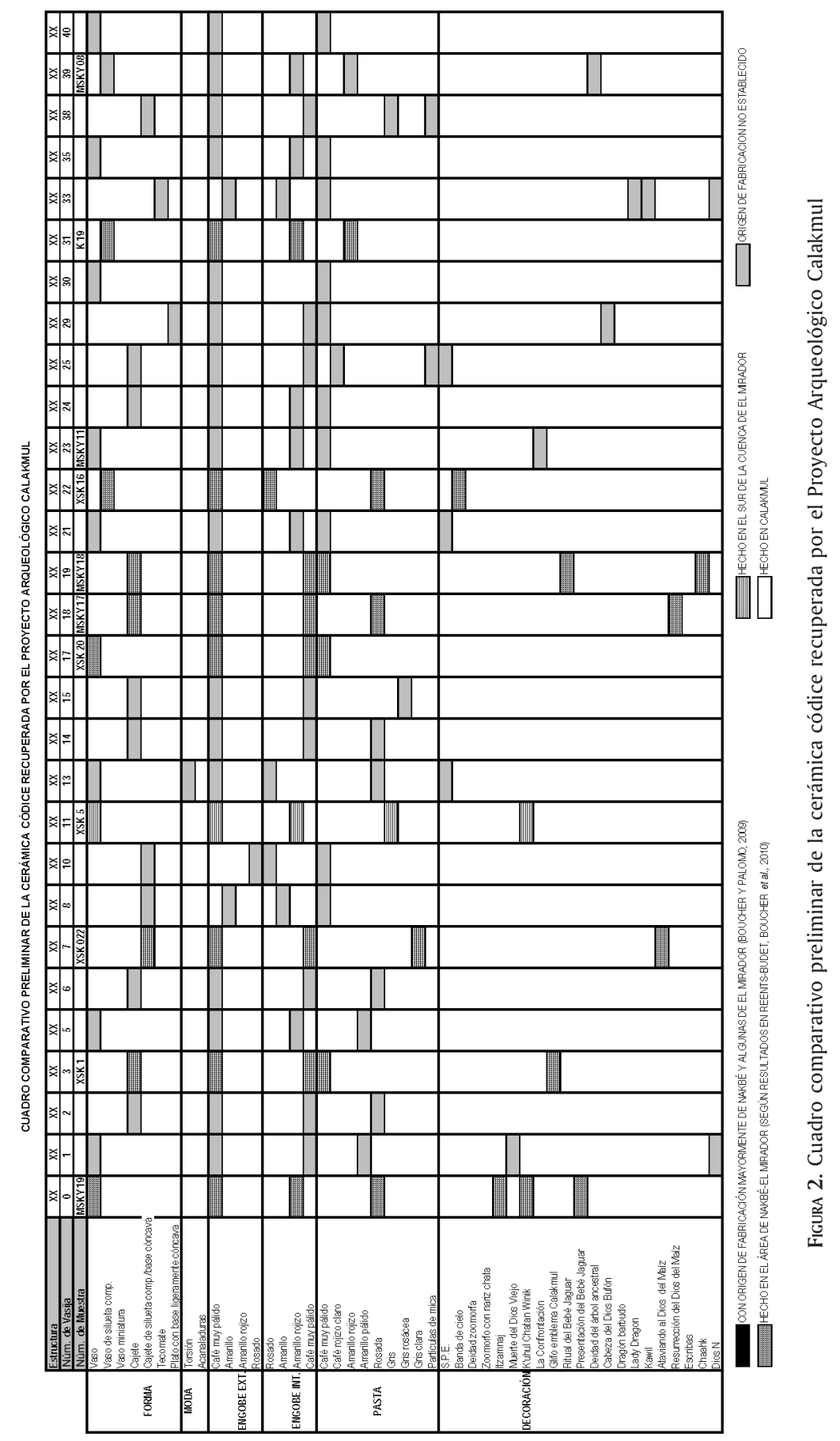




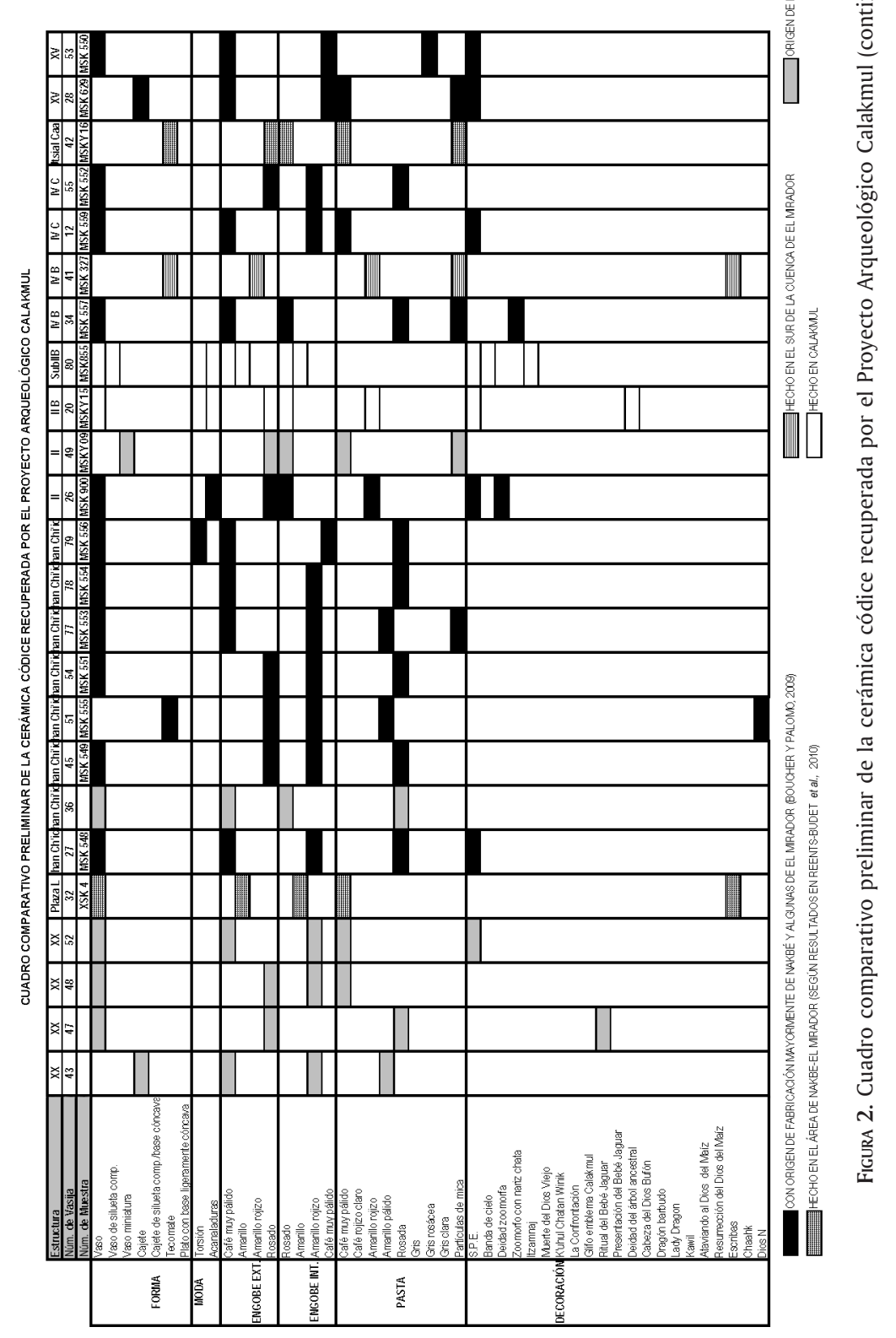


Esta decoración está pintada sobre un engobe mate, sin pulir, de color variable desde café muy pálido (10YR 8/4, 8/3, 8/2,7/3), hacia café amarillento claro (10YR 6/4), amarillo (10YR 8/6, 7/6), amarillo rojizo (7.5YR 7/6), o aún rosado (7.5YR 8/4, $8 / 3,7 / 4)$. Está limitada por bandas en diversas tonalidades de rojo (2.5YR 5/8; 10R $5 / 8,4 / 8$ ), desde el rojo claro (5R 6/4), rojo amarillento (5YR 5/8, 5/6, 4/6), hasta el rojo oscuro (2.5YR 4/8,4/6,3/6; 5R 3/8), en ocasiones con hematita especular (7R 3/8) (ver vasija núm. 19 en Boucher y Palomo, s.f.), aunque también se presentan en color negro (véase vasija núm. 0 en figura 3a). Estas bandas pueden
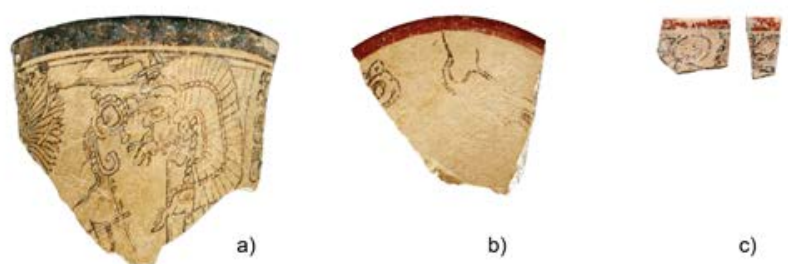

a)

b)

c)
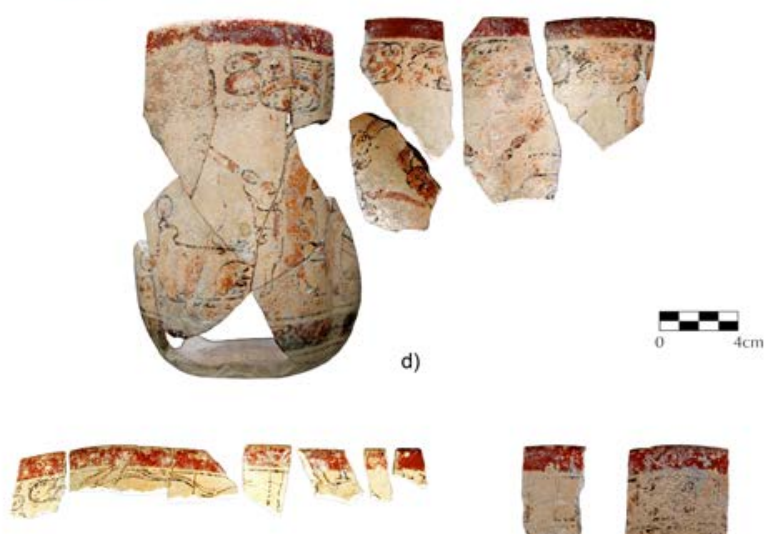

e)
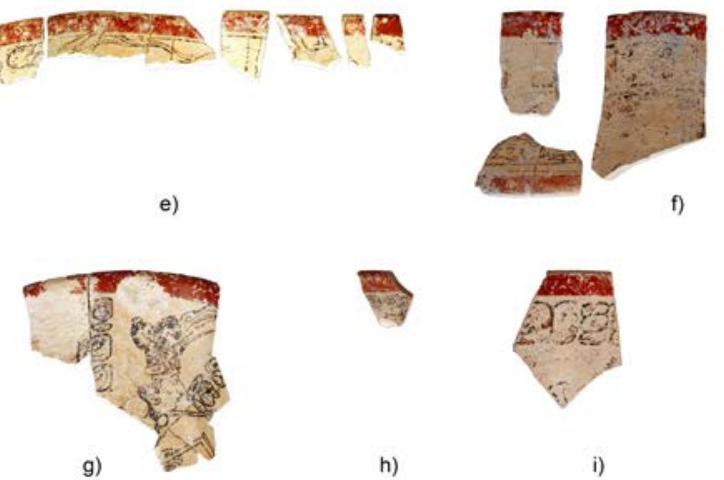

h)

i)
a) Vasija 0 - MSKY19
c) Vasija 14
e) Vasija 21
g) Vasija 23 - MSKY11
i) Vasija 26
b) Vasija 3 - Xsk1
d) Vasija 20
f) Vasija 22 - xSK16
h) Vasija 25
Figura 3 
estar delimitadas por finas líneas negras dobles (ver vasija núm. 22 en figura 3f) o triples. En ocasiones es posible observar sobre las bandas rojas y/o el exterior estuco de color azul postcocción (véase vasija núm. 3 en figura 3b).

Ocasionalmente la pintura negra se aplica a manera de fondo sobre el engobe base claro, logrando la impresión de pintura reservada al negativo. Ejemplos con esta técnica han sido recuperados tanto en Nakbé como en Calakmul (véase Hansen, Bishop y Fahsen, 1991: 232; Reents Budet et al., 1994: 324, vasija núm. 21; Velásquez, 2008: 53; vasija núm. 71 en figura 4r).

Aunque en las escenas retratadas se observa un claro predominio del dibujo a línea sobre la aplicación de áreas de color, es posible observar que ciertas figuras o cartuchos jeroglíficos se enfatizan con discretas líneas rojas o baños diluidos de diversos tonos de color café $(7.5 Y R 5 / 4,4 / 4,4 / 6)$ y rojo oscuro $(2.5 Y R$ 4/8, $3 / 6$ ) que pueden variar hasta rojo amarillento (5YR 5/8) o amarillo (10YR 8/6) (ver vasijas núms. 14 y 60 en fig. 3c y 4q, respectivamente). Esta manipulación en la intensidad de los baños de color café en combinación con la delicadeza de la línea provoca una sensación de contraluz, creando un efecto tridimensional que da solidez a los volúmenes anatómicos y arquitectónicos (Reents Budet, Ball et al., 1994: 11; Velásquez, 2008: 52). El primero en notar la importancia de este rasgo fue Coe (1973: 100). Ya que es mucho más frecuente que lo mencionado en las primeras descripciones de este estilo (véase Reents Budet y Bishop, 1987: 779), proponemos que debería tomarse como elemento diagnóstico.

Forsyth (2002: 673) observó también que el interior de las figuras se realza, a menudo, con una gama de diluciones de color negro-café productoras de un efecto de bicromía más variado que una simple pintura negra sobre una superficie más clara. No obstante, proponemos que en el estilo códice también se presentan vasijas bicromas, de fina línea negra-cafetosa sobre un fondo más claro combinado con un interior amarillo rojizo ${ }^{11}$ (ver vasija núm. 0 en figura 3a; Reents Budet, Ball et al., 1994: 324, fig. 20).

La diversidad en el grosor e intensidad de la línea de color oscuro, que conforman las escenas y los glifos, demuestra el aprovechamiento de todas las posibilidades del pincel para crear segmentos delgados o gruesos en un solo trazo. Con ello se logra, en el mejor de los casos, un efecto caligráfico. Una delgada línea, apenas perceptible, sirve de guía arriba y abajo de los glifos de una variante específica de la fórmula dedicatoria (Secuencia Primaria Estándar) que usualmente ocurre bajo el borde (Hansen, Fahsen y Bishop, 1992: 299). La variación de línea ha proporcionado suficientes detalles artísticos y estilísticos para permitir a distintos autores identificar, aunque de manera a menudo contradictoria, la mano de escribas específicos, talleres y/o "escuelas" (véase Coe, 1973; Robicsek y Hales, 1981; Kerr y Kerr, 1988; Cohodas, 1989; Martin, 1997; Grube, 2004; Delvendahl 2008; García y Carrasco, 2006).

\footnotetext{
${ }^{11}$ Cabe aclarar que no estamos refiriéndonos al tipo Chinos Negro sobre Crema del este del Petén ( $c f$. Reents Budet, Bishop y Fahsen, 1994).
} 

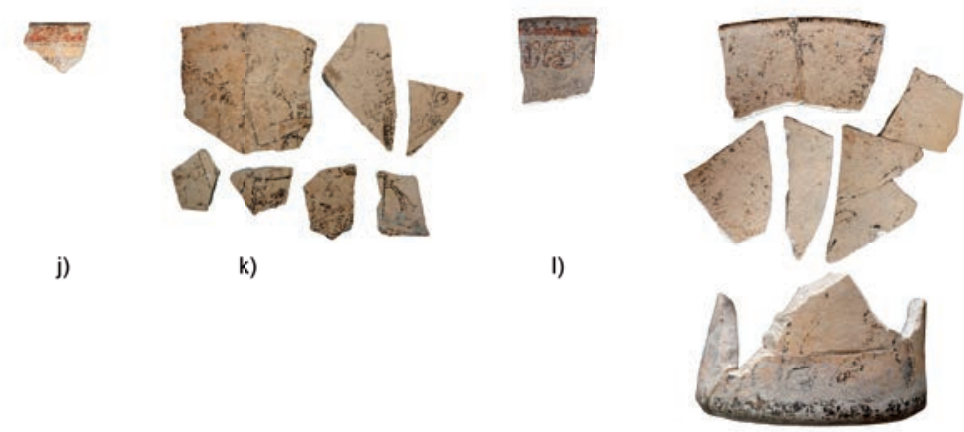

m)

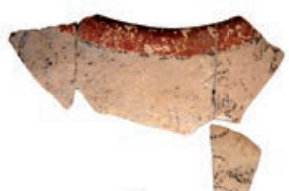

n)

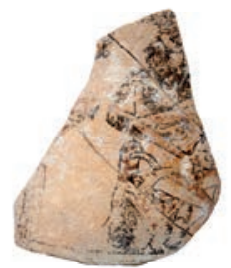

q)

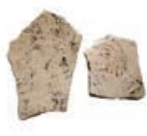

o)
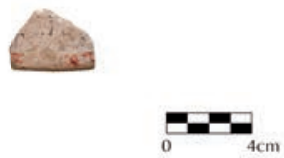

p)

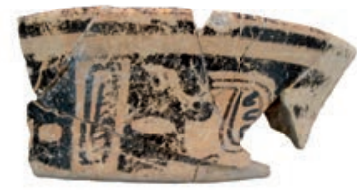

r)

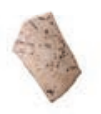

s)
j) Vasija 30
k) Vasija 32 - xSK4
I) Vasija 38
n) Vasija 42 - MSKY16
p) Vasija 49 - MSKYo9
r) Vasija 71
m) Vasija 40
o) Vasija 47
q) Vasija 60
s) Vasija $79 \cdot$ MSK556

Figura 4

En Calakmul se ha podido observar que no sólo algunas bandas rojas con hematita especular muestran partículas brillosas; también hay ejemplos que presentan otras, quizás mica, en el engobe base y en la pasta (véase vasijas núm. 25 en figuras 3h; y 38, 42 y 49, en 3l, 3n y 3p, respectivamente). Por otro lado, también se detectaron estas partículas en pintura anaranjada y roja sobre ciertos tipos policromos ${ }^{12}$ recuperados en Calakmul.

12 Ver Paixban Ante Policromo, Cabrito Crema Policromo y Zacatal Crema Policromo. 
En muchas vasijas donde los diseños están en el exterior, el interior presenta un engobe que Hansen denomina "anaranjado oscuro", sin lectura de Munsell, similar al de las vasijas del tipo cerámico Palmar Anaranjado Policromo (Hansen, Bishop y Fahsen, 1991: 225). En Calakmul, la variabilidad de este color se registra en diversos tonos de amarillo rojizo (7.5YR 7/6, 6/6; 5YR 6/8) hasta el color rosado (7.5YR 8/4, 7/4); y hay ejemplos que, al parecer, carecen de engobe interior (ver vasijas núms. 30, 40 y 47, figuras 3j, 3m y 3o respectivamente). También existe una modalidad decorativa en los cajetes de silueta compuesta, donde el diseño del tema se coloca al exterior cubriendo su base, en tanto que el interior sólo presenta motivos decorativos esquemáticos (ver vasija núm. 7 en Boucher y Palomo, s.f.).

Aunque el estilo códice es abrumadoramente pictórico, con una gran riqueza temática, que en Calakmul incluye narraciones como El sacrificio del Bebé Jaguar, La resurrección del Dios del Maíz, La confrontación y Escribas, entre otras (ver vasijas núms. 19, 18, 23 y 32 en Boucher y Palomo, s.f.; las últimas dos como figuras $3 \mathrm{~g}$ y $4 \mathrm{k}$, respectivamente; sus artistas eligieron diversas modalidades en la disposición de imágenes y textos jeroglíficos: puede haber vasijas que muestran escenas, personajes, listas dinásticas, íconos o cartuchos jeroglíficos. Frecuentemente los personajes están acompañados por breves glosas jeroglíficas. También hay imágenes repetitivas y monoescénicas ${ }^{13}$ que se extienden paralelas bajo la fórmula dedicatoria, o sólo se advierten bandas celestes o jeroglíficas.

El repertorio de formas generalmente incluye vasos cilíndricos así como vasos o cajetes que pueden ser de silueta compuesta con soporte anular incipiente y/o base ligeramente cóncava, con soportes o sin ellos, platos en ocasiones trípodes, fuentes, ollas con cuello restringido y tecomates ( $c f$. Robicsek y Hales, 1981: 4, fig. 3; Hansen, Bishop y Fahsen, 1991: 232; Forsyth, 2002: 672; Boucher y Palomo, s.f.). Velásquez (2008: 52) menciona que hay otras formas menos frecuentes como picheles o tazas con asa, vasos de superficie acanalada y "frascos veneneros”. Estas dos últimas están presentes en el repertorio de Calakmul, además de vasos que presentan una torsión media (ver vasijas núm. 20 en figura 3d; 49 y 79 en 3p y 3s, respectivamente; y vasija núm. 13 en Boucher y Palomo, s.f.).

El último atributo de cerámica códice por caracterizar es la pasta. La recuperada en Calakmul muestra una textura compacta, fina, en ocasiones con inclusiones de mica, de color café predominantemente muy pálido (10YR 8/3, 7/4, 7/3) que puede llegar a un tono rojizo claro (5YR 6/4). También hay ejemplos con pasta de color amarillo pálido (2.Y 8/, 7/3) o rojizo (5YR 6/6, 7.5YR 7/6), algunos de color rosado (7.5YR 8/4, 8/3, 7/4, 7/3; 5YR 8/3, 7/2) y excepcionalmente del color gris $(7.5 Y R$ 6/1) en tono claro $(2.5 Y 7 / 2)$, rosáceo $(7.5 Y R$ 7/2) o muy oscuro (5YR $3 / 1)$.

${ }^{13}$ Cuando se trata de una sola escena que representa un solo momento; se dice "poliescénica" cuando representa una secuencia de momentos (Delvendahl, 2005: 43). 


\section{Análisis empírico}

Cabe mencionar que al estar realizando las sucesivas agrupaciones de los fragmentos, nos llamaron la atención ciertos atributos que podrían resultar diagnósticos de una posible producción de cerámica códice en Calakmul. Entre ellos, la presencia de una torsión media en las vasijas, la forma de cajetes de silueta compuesta con soporte anular incipiente y/o base ligeramente cóncava, el engobe amarillo en el exterior, así como el interior amarillo rojizo y una pasta de color café muy pálido, además de la ausencia de soportes de botón o almena. Quisimos contrastar estos atributos con aquellos de producción foránea, del "grupo de control", para ver si era posible aislar rasgos locales de fabricación.

Al contrastar de manera empírica los ejemplos recuperados en Calakmul, sin origen de fabricación, con los del "grupo de control", podemos resumir, en cuanto a forma, que los primeros exhiben más variedad ya que hemos detectado siete distintas. El "grupo de control" presenta una mayor homogeneidad pues predominan los vasos, con sólo un ejemplo de tecomate y otro de cajete (ver cuadro comparativo, figura 2). La forma de cajete de silueta compuesta con soporte anular incipiente y/o base ligeramente cóncava se reporta en Calakmul (ver vasijas núm. 7 en figura 5b; 8 y 10 en Boucher y Palomo, s.f.; y 38 en fig. 4l). Pero por haber sido ilustrada parcialmente para Nakbé (Hansen, Bishop y Fahsen, 1991: 233, fig. 7b y 7c), no constituye un rasgo distintivo de la producción cerámica de Calakmul.

Se observaron también vasijas con una torsión media en el cuerpo, de silueta compuesta, recuperadas en Calakmul y sin origen, además de otra con origen en la cuenca de El Mirador (ver vasija núm. 13 en Boucher y Palomo, s.f. y 79 en figura 4s). Sin embargo, el ejemplo más notable de este atributo es un vaso de fabricación local, que pertenece al ajuar funerario de Yich' aak K' ahk' en la tumba 4 de la subestructura II B (ver elemento 10/A1 en Boucher y Palomo, 2000: 63, fig. 3; Reents Budet y Bishop en Carrasco et al., 1998: 165, fig. 6B). Otra característica son leves acanaladuras (ver vasija núm. 20, figura 3d). No obstante, ambas características, descritas anteriormente, se notaron también en el "grupo de control" (ver vasijas núm. 79, fig. 4s; y 26, fig. 3i, respectivamente). Por esto, no constituyen rasgos exclusivos asociados con cerámica recuperada o aún fabricada en Calakmul.

En cuanto a la variación en el color del engobe base, (considerado posible elemento diagnóstico), tanto los ejemplos sin origen como los del "grupo de control" llevan los mismos colores, a excepción del engobe amarillo (10YR 7/6) reportado en vasijas de Calakmul. ${ }^{14}$ Cabe notar que Boucher y Palomo (2000: 52) distinguieron el vaso del ajuar de Yich' aak K' ahk' como una nueva variedad códice: engobe amarillo. Asimismo, la forma de silueta compuesta con torsión media, y el texto glífico que incluye el nombre personal de un individuo histórico, llevaron

${ }^{14}$ Otra excepción es el engobe café claro reportado por Hansen, Bishop y Fahsen en Nakbé (1991: 227), informe basado sólo en un vaso semicompleto. 


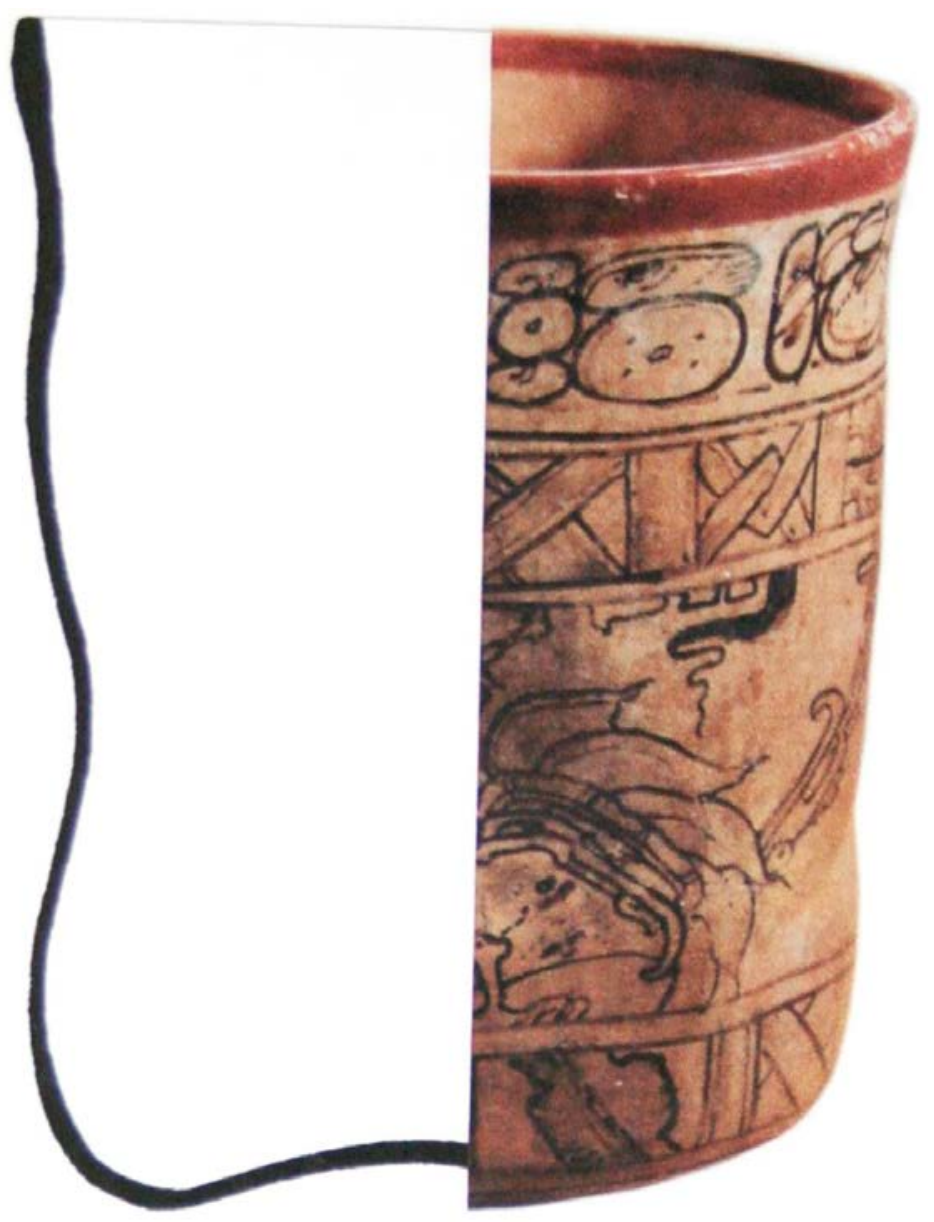

Figura 5a. Corte y foto del vaso núm. 80 con torsión media fabricado en Calakmul

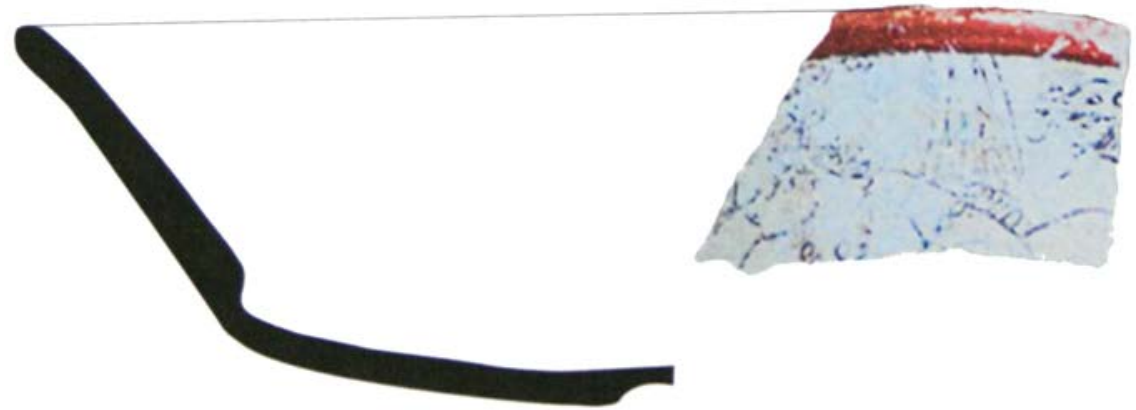

Figura 5b. Corte y foto del cajete núm. 7 de silueta compuesta 
a Reents Budet y Bishop (en Carrasco et al., 1998: 165) a plantear que se trataba de una imitación local de la "auténtica” cerámica estilo códice. Aunque la razón determinante fue su perfil químico, que ellos interpretaron como característico de la producción cerámica de Calakmul.

Posteriormente, Forsyth (2002: 672) también notó que el engobe exterior de la cerámica códice, de la cuenca de El Mirador, tiende a ser comúnmente de color café o amarillo, destacando la diferencia con el engobe crema del tipo Zacatal Crema Policromo; esto contribuiría a su propuesta para designar a aquella como un nuevo tipo. Por ello no se puede seguir considerando este rasgo como característico de la producción de Calakmul.

Otro rasgo, que ha sido pasado por alto, es la posibilidad de considerar el engobe interior como diagnóstico. Pero no se observa predominancia de uno en particular, pues hay igual proporción de ejemplos sin resultados que presentan un engobe amarillo rojizo o café muy pálido, mientras que en el "grupo de control” predomina el primer color (aunque están presentes los otros mencionados anteriormente).

A nivel de pasta, los ejemplos sin resultados muestran predominancia del café muy pálido sobre colores variables. En tanto que en el "grupo de control", aunque ostenta también colores variados, predomina la pasta rosada. Como hemos mencionado anteriormente, la presencia de mica en la pasta es evidente no sólo en ejemplos sin resultados sino también en aquellos (ver vasijas núm. 28, 34 y 77 en Boucher y Palomo, s.f.) del grupo de control. Por lo tanto, este atributo no se puede considerar como relevante para determinar el origen.

Es de llamar la atención la ausencia, en el corpus recuperado en Calakmul, de vasos o cajetes con soportes en forma de pequeñas almenas o botones, a diferencia de los múltiples ejemplos que los exhiben en el corpus de Kerr (ver K 1203, 3230, 6751, 6754; Maya Vase Database, 1989, 1990, 1992, 1994, 1997, 2000 y K 1001; Reents Budet et al., 1994: 326, figura 25).

En resumen podemos concluir que los ejemplos no muestreados y los muestreados sin resultados así como el "grupo de control", recuperados en Calakmul, se traslapan y comparten, aunque diferencialmente, todos los atributos físicos examinados, a excepción del engobe base amarillo; dicha variante había sido interpretada como una imitación local de la "auténtica" cerámica estilo códice. Sin embargo, la caracterización de ésta por Forsyth (2002: 672) con este color no sólo contradice sino que anula esta suposición. Por lo tanto, "empíricamente" al parecer, los fragmentos recuperados en Calakmul no difieren significativamente de los muestreados que han sido asignados a los sitios de Nakbé y El Mirador como su lugar de fabricación.

Por lo cual existe la posibilidad de que los 55 ejemplos de vasijas examinadas, con 17 muestreados sin resultados, podrían ser asignados a futuro a el o los mismos lugares de fabricación que las 13 vasijas del grupo de control. Por otro lado, como hemos explicado previamente, el análisis de los 38 perfiles químicos restantes podría permitir una reevaluación que posiblemente les asignaría un dis- 
tinto lugar o lugares de fabricación. No obstante, Delvendahl (2008: 34) reporta que, de acuerdo con Bishop, las muestras de la Fase II reflejan un perfil químico similar a la cerámica estilo códice de Nakbé.

\section{Contextos de la cerámica códice}

El programa pictórico, plasmado en las escenas de la cerámica códice, se halla no sólo en gran cantidad sino también muestra una unidad temática a pesar de que sus datos composicionales corresponden a distintas fuentes. Además, la abundancia de ejemplos representativos de estilos individuales sugiere que son productos de talleres (Bishop, 1992: 49). Se puede extrapolar de lo anterior que un artista, capaz de pintar compleja iconografía y epigrafía en arte cerámico, fuera también miembro de la élite o estuviera relacionado con una institución o al miembro de un linaje.

Por otro lado, los fragmentos cerámicos, recuperados de un basurero (al lado de una estructura de élite en Buenavista del Cayo, un pequeño centro cívico ceremonial en Belice), abre la posibilidad de la existencia de "talleres-palacio" o "escuela-palacio", como los que existían en la corte mexica de Moctezuma (Taschek y Ball, 1992: 490; Ball, 1993: 258; Bishop, 1992: 49). Es interesante notar que este "taller-palacio" producía vasijas que representan variantes del estilo Holmul $^{15}$ (Bishop, 1992: 47; Reents Budet, Ball et al., 1994: 181, 184) y ya se ha planteado que el artista pudo haber residido en el palacio y ser miembro de la corte local (Ball, 1993). ${ }^{16}$

La mayoría de la cerámica códice, recuperada en la cuenca de El Mirador, proviene exclusivamente de conjuntos residenciales dispersos (Forsyth, 2002: 666). Hasta 2002, la mayor parte de la colección cerámica de la cuenca se recuperó en Nakbé, con algunas muestras encontradas en El Mirador, La Florida y La Muerta (Forsyth, 2002: 672-673). Aunque el mayor volumen de tiestos proviene de Nakbé, fue recuperado únicamente en los grupos Códice y Cimi, al norte del centro del sitio (Forsyth, 2002: 667). Para Forsyth (673), ello sugiere que entre los residentes de estos grupos se incluían artesanos y escribas excepcionales, de estatus relativamente alto, pues las inscripciones en algunas vasijas incluyen títulos usualmente asociados con la élite (Hansen, Bishop y Fahsen, 1991: 232; López y Fahsen, 1994: 73.

En contraste, López y Fahsen (1994: 69-70) reportan que la cerámica códice de la estructura 103, del Grupo Códice, interpretada como "palacio" residencial,

\footnotetext{
${ }^{15}$ Lo que llevó a Reents Budet a sugerir, basada en perfiles químicos y correspondencia en los textos glíficos, que un solo artista podía pintar en estilos diferentes sobre vasijas casi idénticas en forma y tamaño (Bishop, 1992: 48).

${ }^{16}$ Existe otra instancia de fragmentos de vasijas que representan el trabajo de un artista, encontrados junto con desechos domésticos de los basureros asociados al palacio residencial, Est. 103, de Nakbé (Reents Budet, Martin et al., s.f.: 55).
} 
fue utilizada como vajilla cotidiana y al romperse fue integrada a nuevos rellenos arquitectónicos (Velásquez, s.f.: 3). Al parecer, López y Fahsen probablemente se refieren a un contexto secundario de esta cerámica. Anteriormente, Hansen, Bishop y Fahsen (1991: 239-241) habían planteado la posibilidad de que los usuarios de esta cerámica pertenecieran a una posición social intermedia, sepultados en lo que consideraron como modestos montículos en la periferia del sitio. No obstante, las construcciones de piedra labrada con bóvedas y entierros en cistas bajo pisos de estuco atestiguan el estatus del grupo Códice como de élite (Hansen, Bishop y Fahsen, 1991: 240; Velásquez, s.f.: 3).

Foias (2000: 959, figura 5) reporta un basurero en la orilla norte de la Acrópolis de Motul de San José con los desechos de un taller cerámico cercano; allí se encontró una densidad de vasijas parciales y casi completas, quemadas, y por lo menos dos "vasijas-desecho". Ellas muestran un error de cocción por el rápido incremento de temperatura, lo cual hizo explotar la superficie inferior de un vaso de estilo Ik (Foias, 2000: 971, figura 7).

En Calakmul, el contexto donde se recuperó el más alto porcentaje de cerámica códice, hasta el momento, se ubica al sur de la Estructura XX, en la periferia oriental del conjunto palaciego más grande de la ciudad, el grupo Gran Acrópolis. Situada al oeste de la Plaza de los Prisioneros ${ }^{17}$ y del Juego de Pelota, la Estructura XX, un edificio de tres crujías con la fachada orientada al este, probablemente fue el acceso principal al conjunto. Servía para cumplir tanto funciones escénico-ceremoniales, vinculadas con el juego de pelota y el sacrificio humano, como funciones político-administrativas, para la recepción de visitantes, entregas de tributo, etc., tal como se observa en escenas palaciegas sobre cerámica maya del Clásico Tardío (Delvendahl, 2005: 422, 451-456).

De acuerdo con Delvendahl (2005: 433), la Plaza G, atrás de la Estructura XX, es una de las plazas más vinculadas con los espacios públicos de la Gran Acrópolis y funcionaba como área de tránsito hacia el interior del conjunto palaciego. Dos accesos en la sección sur de la Estructura XX daban paso a una plataforma y a escaleras por las cuales se descendía hacia el nivel de la Plaza G. Uno de estos accesos, aquél ubicado en la fachada sur del edificio, fue sellado por los propios mayas en algún momento en la segunda mitad del siglo vilI. Ahí se formó un basurero que se extendió desde la esquina sureste del edificio y su anexo sur, por la plataforma, hacia el nivel de la plaza, constituyendo un mismo contexto arqueológico (Delvendahl, 2005: 454; 2008: 125-128). Los materiales de este contexto se asocian con la élite gobernante, aunque también incluían vasijas de uso doméstico como las ollas estriadas Ciricote Compuesto y vajillas de servicio del grupo Tinaja e Infierno (Delvendahl, 2003: 66-67).

En la capa C del pozo núm. 1 de la Plaza G (núm. de control 1822), excavado en 2001 en una esquina de la plaza directamente al sur de la Estructura XX, se recuperaron 7950 tiestos de cerámica. Estos incluyen un fragmento de vasijas

\footnotetext{
${ }^{17}$ Que presenta esculpida en roca madre siete presos mutilados.
} 
de alabastro así como una gran cantidad de piezas policromas del Clásico Tardío y restos de varias vasijas, así como fragmentos de estilo códice que muestran el glifo emblema "cabeza de serpiente", el título K'uhul Chatahn Winik, y referencias a Yuknoom Took K'awil, uno de los últimos gobernantes de la dinastía Kaan (Delvendahl, 2005: 434-436, 454). La capa C presentó $42.79 \%$ de materiales del Clásico Temprano y 48.77 \% del Clásico Tardío (Delvendahl, 2003: 62-67). La alta proporción de materiales del Clásico Temprano es debida en parte a la inclusión de las ollas estriadas Ciricote Compuesto dentro de este horizonte, aunque continuaron en uso durante el Clásico Tardío.

También se recuperaron fragmentos de cerámica códice en unidades residenciales que se pueden considerar palaciegas: Utsiaal Caan, al nivel más bajo, al norte del grupo Gran Acrópolis; y el pequeño grupo Chan Chi'ich, al noreste de la Gran Plaza. Esta podía ser una unidad residencial de la elite no gubernamental, dado su tamaño y la menor calidad de sus materiales de construcción (Delvendahl, 2005: 413). Delvendahl (2005: 457, 463) plantea que, si no fue habitado por la realeza local, la unidad habitacional Utsiaal Caan podría representar un conjunto separado y cerrado en sí, que posiblemente era ocupado temporalmente por visitantes importantes con su séquito. De acuerdo con Delvendahl (2005: 463), la cantidad y ubicación de la cerámica estilo códice encontrada hasta ahora en el grupo Gran Acrópolis no permite conclusiones sobre la existencia de posibles talleres o escuelas de arte ${ }^{18}$ adentro del conjunto palaciego. La presencia de materiales códice en la pequeña Plaza L, uno de los más retirados y menos accesibles de los 17 patios del conjunto, posiblemente se deba a un uso privado y ceremonial de dicha sección.

Desafortunadamente, no tenemos datos cuantitativos ni suficientes detalles arqueológicos para poder comparar el basurero asociado al palacio "taller" o "escuela" de Buenavista, y/o la estructura palaciega 103 (saqueada y del Grupo Códice en Nakbé), así como el basurero en la orilla norte de la Acrópolis de Motul de San José, con los datos del basurero de la Plaza G (asociada a la Estructura XX del grupo Gran Acrópolis) y/o con los datos de las unidades residenciales de élite Utsiaal Caan y Chan Chi'ich, para poder aseverar si los dos primeros contextos se reproducen en Calakmul. Ya que, aparentemente sin discusión de criterios, Taschek y Ball (1992; Ball, 1993) interpretan el basurero asociado al palacio de Buenavista como indicativo de un posible taller o escuela, mientras que Delvendahl (2005: 463) por ubicación y contenido niega esta posibilidad para el basurero de la Estructura XX.

Últimamente Reents Budet et al. (s.f.: 56) han propuesto otra interpretación: las vasijas y/o fragmentos pintados de los basureros de los palacios de Buenavista y de Nakbé serían el resultado de los banquetes o festines celebrados para consolidar relaciones políticas y de prestigio social. Una interpretación que se

${ }^{18}$ Se ha planteado recientemente que los conceptos taller y especialización son inadecuados para describir la producción de vasijas policromas mayas (cf. Rice, 2009). 
ajusta especialmente bien a los materiales arqueológicos del basurero y los rasgos arquitectónicos de la Estructura XX de Calakmul.

Una interpretación alternativa plantea que Nakbé pudo haber sido destino de peregrinaciones para venerar ancestros durante el Clásico Tardío. La cerámica códice se producía como objeto ritual, depositario de conocimientos cosmológicos y mitológicos asociados con los aspectos más fundamentales de la religión; el Grupo Códice tendría una función mortuoria como lugar predilecto para las tumbas de sabios y artistas (Reents Budet et al., s.f.: 39).

\section{Consideraciones finales}

Cohodas (1989: 203) notó que algunos vasos dinásticos, publicados por Robicsek y Hales (1981: vasijas núm. 122, 126; Kerr 999, 955), hoy en el Museo de Bellas Artes de Boston, presentaban pintura completamente moderna aunque imita estilos de distintos pintores. Sin embargo, estos vasos fueron muestreados por Reents Budet et al. (s.f.: 50, nota 26) quienes aseguran que su huella química corresponde a Nakbé. Existe la posibilidad de la existencia de vasijas prehispánicas repintadas en tiempos modernos. Pero también pudo haber vasijas de la cuenca sin decorar que llegaron a Calakmul para ser pintadas. Asimismo, es posible que un gran maestro pintara un ejemplo y sus aprendices lo usaran de modelo para hacer copias. $\mathrm{O}$, finalmente, que los artistas pudieron desplazarse.

La calidad de la cerámica códice, que se considera en general de buena a excelente, se relaciona en Calakmul con una distribución limitada a los contextos sociopolíticos de la clase letrada. Además cumpliría una función funeraria, ${ }^{19}$ relacionada con el culto a los ancestros, como lo descubre su presencia en tumbas de élite de la Estructura II, rectora del sitio: vasijas casi completas fueron recuperadas principalmente en conjuntos residenciales de piedra labrada y especialmente en asociación con un basurero. Esto último nos hace plantear una relativa facilidad para conseguir la cerámica códice y cuestionar la función que podía tener ésta, si al romperse fue tirada a la basura (Delvendahl, 2005: 464).

Los consumidores de cerámica códice en la cuenca representan un grupo específico de miembros de la élite relacionados con Calakmul a través de los textos pintados en las vasijas ya que dos títulos K'uhul Chatahn Winik' y K'uhul Sak Waya's, se encuentran en las inscripciones pétreas o pintadas de Calakmul; además, los vasos dinásticos muestran una antigua lista de reyes que comparten el glifo emblema y ciertos nombres personales con algunos de los gobernantes del Clásico en Calakmul, creando, de acuerdo con Reents Budet, Martin, Hansen y Bishop (s.f.: 40), un puente entre el mítico y legendario pasado y el Clásico Tardío.

${ }^{19}$ Función deducida posiblemente más por la recuperación arqueológica que por un fenómeno sistémico. 
Los mayas del Clásico bien pudieron haber circulado bienes de prestigio más por razones políticas que con fines económicos (Houston, Stuart y Taube, 1992: 506). Obsequios reales como vasijas y otros objetos pueden haber ayudado a confirmar alianzas, consolidar acuerdos y conectar centros rectores con las periferias. Miembros de la élite pudieron haber tomado cacao u otras bebidas en los vasos para sellar acuerdos o celebrar importantes reuniones. Tal vez toda comunicación formal entre centros mayores, ya fueran aliados o enemigos, pudieron haber involucrado la transmisión de bienes preciados, consolidando pactos sociales y políticos, plasmando los nombres de sus destinatarios o propietarios sobre las vasijas.

Aparentemente la élite de Naranjo distribuía vasijas con textos dinásticos que hacían referencia a sus gobernantes, a Tikal, Holmul, Río Azul y Ucanal (Houston, Stuart y Taube, 1992: 506). La corte real de los aguerridos Yuknoom de Calakmul pudo haber encargado o comisionado vasijas de estilo códice a los sabios intelectuales, que residían en Nakbé, como trofeos de guerra o como tributo para consolidar el reino de Kaan y legitimar su linaje.

\section{BIBLIOGRAFÍA}

Ball, W. Joseph

1993 "Pottery, Potters, Palaces and Polities: Some Socioeconomic and Political Implications of Late Classic Maya Ceramic Industries", New Perspectives on Classic Maya Civilization: Lowland Civilization in the Eighth Century A.D. 243272. Dumbarton Oaks: Trustees for Harvard University (Research Library and Collection).

Bishop, Ronald

1984 "Análisis por activación de neutrones de la cerámica de El Mirador". Mesoamérica. Número Especial: El Mirador. Cuaderno No. 7: 103-111. Antigua, Guatemala: Centro de Investigaciones Regionales de Mesoamérica.

1992 "Pre-Columbian Pottery: Research in the Maya Region", Archaeometry of PreColumbian Sites and Artifacts: 15-65. Proceedings of a Symposium UCLA Institute of Archaeology the Getty Conservation Institute, Los Angeles.

2003 "Five Decades of Maya Fine Orange Ceramic Investigation by INAA". Patterns and Process: 81-91. A Festschrift in honor of Dr. Edward V. Sayre. Suitland, Maryland: Smithsonian Center for Materials Research and Education.

Bishop, Ronald L., M. J. Blackman, Richard Hansen, Dorie Reents Budet y Erin L. Sears

s.f. "Ceramic Paste Variation in the Mirador Basin: A Regional Perspective", Mecanuscrito. Mérida: Centro INAH Yucatán.

Boucher, Sylviane

1997 "The Ceramics of Tomb 4, Structure II, from Calakmul, Campeche”. Ponencia presentada en el V Simposio Annual Maya de Brevard Community College's 
Institute for Latin American Studies. Mecanuscrito. Mérida: Centro INAH Yucatán.

Boucher, Sylviane y Sara Dzul

2006 "La secuencia tipológica preliminar de la cerámica del Proyecto Arqueológico Calakmul, Campeche (Temporadas 1993-2000)”, Los mayas de ayer y hoy. Memorias del Primer Congreso Internacional de Cultura Maya. Tomo I. Mérida: Gobierno del Estado de Yucatán / Consejo Nacional para la Cultura y las Artes / Instituto Nacional de Antropología e Historia / Universidad Autónoma de Yucatán, 584-616.

Boucher, Sylviane y Yoly Palomo

2000 "El lenguaje iconográfico de la Tumba 4, Estructura II de Calakmul, Campeche”, Los Investigadores de la Cultura Maya, 8: 49-68. Campeche: Universidad Autónoma de Campeche.

s.f. "Catálogo de vasijas estilo códice del Proyecto Arqueológico Calakmul". Mecanuscrito. Mérida: Centro InAH Yucatán.

Carlson, John B.

1988 "Skyband Representations in Classic Maya Vase Painting", Maya Iconography: 277-293. Princeton: Princeton University Press.

Carrasco, Ramón, Sylviane Boucher y Paula Álvarez

2005 "Una revisión histórica sobre Garra de Jaguar, gobernante de Calakmul en el siglo vil”, IV Coloquio de Arqueología Pedro Bosh Gimpera, vol. II, Ernesto Vargas Pacheco (ed.). México: Universidad Nacional Autónoma de México, Instituto de Investigaciones Antropológicas, 775-794.

Carrasco, Ramón, Sylviane Boucher, Emyly González, Yoly Palomo, Paula Alvarez, Luz. E. Campaña, Vera Tiesler, Dorie Reents Budet, Ronald Bishop, Valeria García, Josefina Granados, Renata García, Sara Dzul, Simon Martin y Javier Vázquez

1998 "Informe de los trabajos arqueológicos emporada 1997-1998 del Proyecto Arqueológico Calakmul”. Mecanuscrito. Archivo del Centro inaH, Campeche.

Carrasco, Ramón

2008 "Arqueología-epigrafía. Dos historias paralelas". Ponencia presentada en la Sexta Mesa Redonda de Palenque, 16-21 de noviembre, Palenque, Chiapas.

Coe, Michael

1973 Maya Scribe and His World. Nueva York: Grolier Club.

Cohodas, Marvin

1989 "Transformations: Relationships between Image and Text in the Ceramic Painting of the Metropolitan Master", World and Image in Maya Culture Explorations in Language, Writing and Representation. Salt Lake City: University of Utah Press, 198-231. 
Delvendahl, Kai

2003 "Análisis del material cerámico recuperado en las investigaciones del Grupo Gran Acrópolis durante la temporada 2001 del Proyecto Arqueológico Calakmul, Campeche”. Mecanuscrito. Centro INAH Yucatán, Mérida.

2005 "Las sedes del poder. Arquitectura, espacio, función y sociedad de los conjuntos palaciegos del Clásico Tardío en el área maya evaluados desde la arqueología y la iconografía". Tesis de doctorado en Estudios Mesoamericanos. México: Universidad Nacional Autónoma de México, Facultad de Filosofía y Letras, Instituto de Investigaciones Filológicas.

2008 Calakmul in Sight. History and Archaeology of an Ancient Maya City. Mérida: Unas Letras Industria Editorial.

Domínguez Carrasco, María del Rosario

1994 Calakmul, Campeche: un análisis de la cerámica. Campeche: Universidad Autónoma de Campeche, Centro de Investigaciones Históricas y Sociales (Colección Arqueología, 4).

Domínguez, Carrasco María del Rosario, Dorie Reents Budet, Ronald L. Bishop y William Folan

1998 "La cerámica de Calakmul: análisis químico y sociopolítico”, Los Investigadores de la Cultura Maya, 6: 361-375. Campeche: Universidad Autónoma de Campeche.

Foias, Antonia E.

2000 "Entre la política y economía: resultados preliminares de las primeras temporadas del Proyecto Arqueológico Motul de San José”, XIII Simposio de Investigaciones Arqueológicas en Guatemala (1999). Guatemala, Guatemala: Museo Nacional de Arqueología y Etnología, 945-974.

Folan, William J. y Abel Morales López

1996 "Calakmul, Campeche, México: la Estructura II H, sus entierros y otras funciones ceremoniales y habitacionales", Revista Española de Antropología Americana (26): 9-28. Madrid: Servicio Publicaciones Universidad Complutense de Madrid.

Forsyth, Donald

1989 The Ceramics of El Mirador, Peten, Guatemala. Provo: El Mirador Series. Part 4 (Papers of the New World Archaeological Foundation, 63).

1993 "The Ceramic Sequence at Nakbe, Guatemala", Ancient Mesoamerica (4) 3153. Cambridge: Cambridge University Press.

2002 "La cerámica del Clásico Tardío de la cuenca de El Mirador”, XVI Simposio de Investigaciones Arqueológicas en Guatemala. Guatemala: Museo Nacional de Arqueología y Etnología, 665-678.

García, Ana y Ramón Carrasco

2006 "Algunos fragmentos cerámicos de Estilo Códice procedentes de Calakmul", Los Investigadores de la Cultura Maya, 14: 125-136. Campeche: Universidad Autónoma de Campeche. 
Gifford, James C.

1976 Prehistoric Pottery Analysis and the Ceramics of Barton Ramie in the Belize Valley. Cambridge: Harvard University (Memoirs of the Peabody Museum of Archaeology and Ethnology, 18).

Grube, Nikolai

2004 "El origen de la dinastía Kaan”, Los Cautivos de Dzibanche, Enrique Nalda (ed.). México: Instituto Nacional de Antropología e Historia, 117-131.

Grube, Nikolai e Iken Paap

2008 "Informe de los trabajos de levantamiento topográfico en Uxul (Campeche)". Universidad de Bonn, Instituto de Antropología Americana. Mecanuscrito. Archivo del Centro INAH Campeche, Campeche.

Hansen, Richard D., Ronald L. Bishop y Federico Fahsen

1991 "Notes on Maya Codex Style Ceramics from Nakbe, Peten, Guatemala", Ancient Mesoamerica (2): 225-243. Cambridge: Cambridge University Press.

Hansen, Richard, Federico Fahsen y Ronald L. Bishop

1992 "Escribas, códices y vasos: estudio de un vaso códice de Nakbe, Peten", $V$ Simposio de Investigaciones Arqueológicas en Guatemala. Guatemala: Museo Nacional de Arqueología y Etnología, 297-303.

Houston, Stephen D., David Stuart y Karl Taube

1992 "Image and Text on the Jauncy Vase", The Maya Vase Book, vol. 3. Nueva York: Kerr Associates, 499-509.

Kerr, Justin

1989 The Maya Vase Book. A Corpus of Rollout Photographs of Maya Vases, vol. 1. Nueva York: Kerr Associates.

1990 The Maya Vase Book. A Corpus of Rollout Photographs of Maya Vases, vol. 2. Nueva York: Kerr Associates.

1992 The Maya Vase Book. A Corpus of Rollout Photographs of Maya Vases, vol. 3. Nueva York: Kerr Associates.

1994 The Maya Vase Book. A Corpus of Rollout Photographs of Maya Vases, vol. 4. Nueva York: Kerr Associates.

1997 The Maya Vase Book. A Corpus of Rollout Photographs of Maya Vases, vol. 5. Nueva York: Kerr Associates.

2000 The Maya Vase Book. A Corpus of Rollout Photographs of Maya Vases, vol. 6. Nueva York: Kerr Associates.

s.f. The Maya Vase Database < http://research.famsi.org/kerrmaya.html>. [Consultada el 21 de mayo del 2012].

Kerr, Barbara y Justin Kerr

1988 "Some Observations on Maya Vase Painters", Maya Iconography: 236-259. Princeton: Princeton University Press.

López, Roberto y Federico Fahsen

1994 "Nuevas referencias sobre cerámica códice en contexto arqueológico en 
Nakbe”, VII Simposio de Investigaciones Arqueológicas de Guatemala (1993). Guatemala: Museo Nacional de Arqueología y Etnología, 59-79.

Martin, Simon

1997 "The Painted King List. A Commentary on Codex Style Dynastic Vases", The Maya Vase Book, vol. 5. Nueva York: Kerr Associates, 846-867.

Munsell Soil Color Charts

1973 Munsell Color. Nueva York: Macbeth Division of Kollormorgen Corporation.

Pallan, Gayol Carlos y Erik Velásquez García

2005 "Vasos mayas con secuencia primaria estándar en una colección mexicana. Análisis epigráficos e implicaciones históricas", Los Investigadores de la Cultura Maya, 13: 525-536. Campeche: Universidad Autónoma de Campeche.

Reents Budet Dorie y Ronald L. Bishop

1987 “The Late Classic Maya 'Codex Style’ Pottery”, Memorias del Primer Coloquio Internacional de Mayistas, 5-10 de agosto de 1985, vol. I. México: Universidad Nacional Autónoma de México, 775-789.

2003 "More Than Methodology: INAA and Classic Maya Painted Ceramics". Patterns and Process. Suitland [Estados Unidos]: Smithsonian Center for Materials Research and Education, 93-106.

Reents Budet, Dorie, Joseph W. Ball, Ronald L. Bishop, Virginia M. Fields y Barbara MacLeod

1994 Painting the Maya Universe: Royal Ceramics of the Classic Period. Durham [Estados Unidos] y Londres: Duke University Press.

Reents Budet, Dorie, Ronald L. Bishop y Federico Fahsen

1994 "Una cerámica Maya Negro sobre Crema del período Clásico Tardío de la Región Oriental de Petén, Belice”, VII Simposio de Investigaciones Arqueológicas en Guatemala. Guatemala: Museo Nacional de Arqueología y Etnología / Ministerio de Cultura y Deportes / Instituto de Antropología e Historia / Asociación Tikal, 49-67.

Reents Budet, Dorie, Simon Martin, Richard D. Hansen y Ronald L. Bishop

1997 "Codex Style Pottery: Recovering Context and Concept". Ponencia presentada en el Texas Symposium "In their Own Write: Native Voices of Mesoamerica”. The Maya Meeting at Texas, 6-7 de marzo. University of Texas, Austin.

1998 "Codex Style Pottery: Recovering Context, Narrative and Meaning”. Ponencia presentada en el $14^{\text {th }}$ Maya Hieroglyph Workshop, abril (de acuerdo al manuscrito de los autores). University of Texas, Austin.

s.f. "Codex Style Pottery: Recovering Context, Narrative and Meaning". Mecanuscrito proporcionado por los autores. Versión del 25 de octubre del 2000 (proyectado para su publicación en 2010 por Richard Hansen). 
Reents Budet, Dorie, Sylviane Boucher, Yoly Palomo, Ronald Bishop y James Blackman

2010 "Cerámica de estilo códice: nuevos datos de producción y patrones de distribución". Ponencia presentada en el XXIV Simposio de Investigaciones Arqueológicas en Guatemala el 13 de julio, ciudad de Guatemala.

Rice, Prudence

2009 "Late Classic Maya Pottery Production: Review and Synthesis", Journal of Archaeological Method and Theory, 16 (2): 117-156. Nueva York: Plenum, Press.

Robicsek, Francis y Donald M. Hales

1981 The Maya Book of the Dead. The Ceramic Codex. Charlottesville: University of Virginia Art Museum.

Smith, Robert y James Gifford

1966 Maya Ceramic Varieties, Types and Wares at Uaxactun: Supplement to "Ceramic Sequence at Uaxactun”. Nueva Orleans: Tulane University (Middle American Research Institute, Publication 28), 125-174.

Smith, Robert, E. Gordon, R. Willey y James Gifford

1960 "The Type Variety Concept as a Basis for the Analisis of Maya Pottery", American Antiquity, 25 (3): 330-340. Salt Lake City: The Society for American Archaeology.

Taschek, Jennifer y Joseph Ball

1992 "Lord Smoke Squirrel's Cacao Cup: The Archaeological Context and Sociohistorical Significance of the Buenavista "Jauncy Vase", The Maya Vase Book, vol. 3: 490-497. Nueva York: Kerr Associates.

Velásquez, Erik

2008 "El vaso de Princeton”, Arqueología Mexicana, XVI (93): 51-59. México: Raíces / Instituto Nacional de Antropología e Historia.

s.f. "Los vasos del reino de Chatahn: una manifestación de la cerámica del estilo códice”. Mecanuscrito. Archivo de las Autoras, Centro inah Yucatán, Mérida. 